\title{
Ultrasonography of pediatric urogenital emergencies: review of classic and new techniques
}

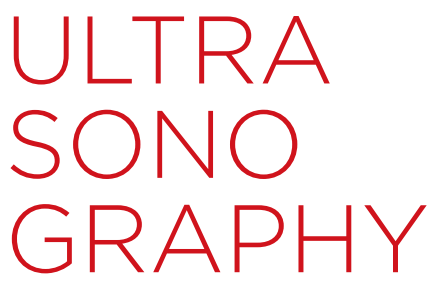

\author{
Masahiro Kitami \\ Department of Diagnostic Radiology, Tohoku University Graduate School of Medicine, \\ Sendai, Japan
}

Keywords: Ultrasonography; Elasticity imaging techniques; Contrast media; Testis; Emergencies; Pediatrics

Urogenital emergencies are fairly common in the pediatric population, and a timely and correct diagnosis is necessary to avoid possible future infertility. In this field, ultrasonography is essential, as it has the advantages of being radiation-free and readily accessible. In particular, a high-frequency transducer allows precise evaluation of the morphology and vascularity of the scrotum, which is on the surface of the body. Beyond conventional techniques, new advanced imaging techniques have been developed, including elastography and contrast-enhanced ultrasonography. However, several pitfalls remain in the diagnosis of urogenital diseases using ultrasonography. Thus, accurate knowledge and sufficient experience with the technique are essential for making a correct diagnosis. This review provides an overview of pediatric urogenital emergency pathologies and recent ultrasonography techniques.

\section{Introduction}

In the pediatric population, urogenital emergencies are quite common, and may have serious consequences. They include testicular torsion, epididymitis, testicular appendage torsion, testicular trauma, acute idiopathic scrotal edema (AISE), ovarian torsion, and emergencies involving associations of urogenital anomalies such as Wunderlich syndrome. These diseases are diverse, and there are pitfalls in their diagnosis. Along with conventional ultrasonography (US), new techniques have been developed, such as contrast-enhanced US (CEUS), tissue elastography, and 3-dimensional sonography. CEUS is used off-label in children, but a recent review suggested that the use of US contrast agents is safe in children [1]. These new techniques are also presented in this review.

\section{Testicular Torsion}

An etiological study of acute conditions of the scrotum showed that the distribution of diseases varied according to age [2]. In younger children ( $0-12$ years), appendage torsion was most common (47\%), followed by testicular torsion (34\%) and epididymitis (4\%). In those aged 13-21 years,

\section{REVIEW ARTICLE}

https://doi.org/10.14366/usg. 17011 pISSN: 2288-5919 - elSSN: 2288-5943

Ultrasonography 2017;36:222-238

Received: February 10, 2017

Revised: March 18, 2017

Accepted: March 30, 2017

Correspondence to:

Masahiro Kitami, MD, Department of Diagnostic Radiology, Tohoku University Graduate School of Medicine, 2-1 Seiryo-cho, Sendai, 980-8574, Japan

Tel. $+81-22-717-7312$

Fax. +81-22-717-7316

E-mail: mshkitami@rad.med.tohoku. ac.jp
This is an Open Access article distributed under the terms of the Creative Commons Attribution NonCommercial License (http://creativecommons.org/ icenses/by-nc/3.0/) which permits unrestricted noncommercial use, distribution, and reproduction in any medium, provided the original work is properly cited.

Copyright (C) 2017 Korean Society of Ultrasound in Medicine (KSUM)

How to cite this article:

Kitami M. Ultrasonography of pediatric urogenital emergencies: review of classic and new techniques. Ultrasonography. 2017 Jul;36(3):222-238. 
testicular torsion dominated (86\%), followed by appendage torsion $(9 \%)$. Thus, testicular torsion should always be considered in the differential diagnosis, especially in adolescents.

Testicular torsion is a true emergency and is of the most concern among acute scrotum conditions. Testicular torsion is the rotation of the testis with torsion of the spermatic cord; this leads to vascular insult, which results in testicular ischemia and ultimately necrosis. The golden time for torsion reduction is $6-8$ hours. The salvage rate is almost $100 \%$ if treated within 6 hours after onset but decreases quickly with time, declining to $70 \%$ within $6-12$ hours and 20\% within 12-24 hours [3]. Thus, the correct diagnosis and prompt reduction are essential. However, nearly $50 \%$ of clinically diagnosed cases of testicular torsion are false-positives [3], making a sonographic diagnosis especially important.

There are two representative types of testicular torsion: extravaginal and intravaginal. Intravaginal torsion is much more common than extravaginal torsion.

\section{Intravaginal Torsion}

Intravaginal twisting of the spermatic cord occurs due to excessive mobility of the testis and spermatic cord, owing to the abnormal attachment of the tunica vaginalis, which is known as the "bellclapper deformity" [4]. This type of torsion occurs commonly in adolescents, although it also occurs in neonates. The estimated frequency is 4 per 100,000 for boys aged $<18$ years [5].

The typical presentation is scrotal pain with sudden onset and subsequent scrotal swelling. However, in one study the initial symptoms were abdominal pain and vomiting without scrotal pain in $11 \%$ (9 of 84 ) of patients [6]. In a series published by Pogorelic et al. [6], the scrotum was not evaluated in six of nine patients, and five testicles were lost due to necrosis. Testicular torsion should always be kept in mind in the differential diagnosis of cases of lower abdominal pain [6].

On gray-scale sonography, the echotexture is initially normal. After 4-6 hours, the testicular echotexture shows a low echoic signal due to edema and swelling (Fig. 1A, B). After 24 hours, it becomes more heterogeneous, reflecting congestion, ischemia, and/or hemorrhage [3]. Heterogeneity of the testis suggests nonviability, whereas a homogenous echotexture bodes extremely well for testicular viability [7].

Using color Doppler or power Doppler, the vascularity of the testis can be evaluated. Decreased or absent affected testicular flow has a sensitivity of $86 \%-100 \%$, and a specificity of $97.9 \%-100 \%$ [8-11]. Power Doppler is more sensitive in detecting testicular flow than is color Doppler ( $97 \%$ vs. $88 \%$ ) [12]. This method is very valuable because of its simplicity, feasibility, high sensitivity, and high specificity. However, apparently preserved vascularity on color
Doppler does not exclude testicular torsion. Testicular torsion may present as hyperemia in its early stages due to venous dilation and preserved arterial flow $[13,14]$. In such cases, the spectral wave form may be informative, showing an increased testicular resistance index with absent diastolic flow, indicating severe venous obstruction [13]. False-negative Doppler evaluations can also occur in the setting of spontaneous detorsion or intermittent torsion [15]. Intermittent torsion can exhibit hyperemia [16] and may be misdiagnosed as orchitis. A horizontal testicular position $[17,18]$ and episodes of pain relief are useful for making a correct diagnosis. A quarter of cases of intermittent torsion have repeated episodes [19], and recurrent episodes are highly suggestive of intermittent testicular torsion when other causes have been excluded $[19,20]$.

Although color Doppler and power Doppler images have high sensitivity and specificity, they are used to identify indirect findings suggestive of testicular torsion. The most direct finding with respect to testicular torsion is a twisted spermatic cord, referred to as the "whirlpool sign" (Fig. 1C, D) [16]. Indeed, the sensitivity and specificity of the whirlpool sign are up to $100 \%[16,21,22]$. The whirlpool sign is also useful in cases of incomplete torsion, in which testicular vascularity may be preserved. Thus, the whirlpool sign should be carefully sought to avoid this pitfall, even if testicular vascularity is preserved. The location of the twisted spermatic cord varies: from just distal to the external ring to above or posterior to the testis [16]. In the case of an undescended testis, a twisted spermatic cord may be located in the inguinal canal. Thus, the entire route should be screened when seeking a twisted spermatic cord [16].

Observation of the epididymis is also important. Galina et al. [23] showed that the position and morphology of the epididymal head were abnormal in all nine of the boys in that study with acute testicular torsion but preserved testicular flow. This was also true in four cases with apparently normal-looking spermatic cords. That is, an abnormal configuration and displaced position of the head of the epididymis may be the only sonographic findings indicative of torsion. Thus, observation of the epididymis is especially important in cases of incomplete torsion with preserved testicular flow. Additionally, reactive hydrocele and scrotal wall thickening may be seen $[7,23,24]$.

Similar to Doppler images, CEUS may show a lack of intratesticular enhancement $[14,25]$. Although no advantage over Doppler US has been found in the few series that have been published [25], CEUS has the potential to provide improved sensitivity in detecting flow in the pediatric testis during infancy because it is often difficult to demonstrate perfusion within a normal testis using color Doppler sonography [25]. Moreover, CEUS can add useful information for evaluating segmental infarction, which may be secondary 


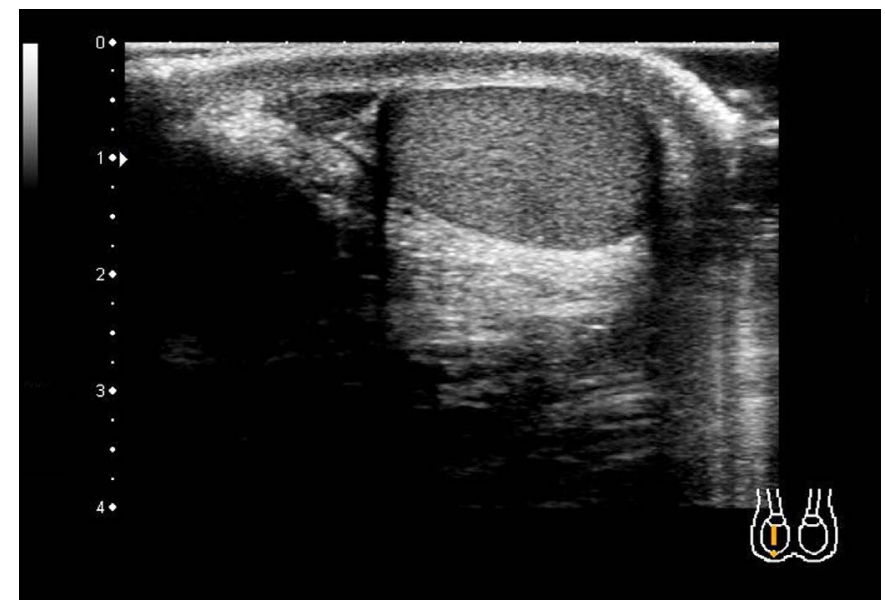

A

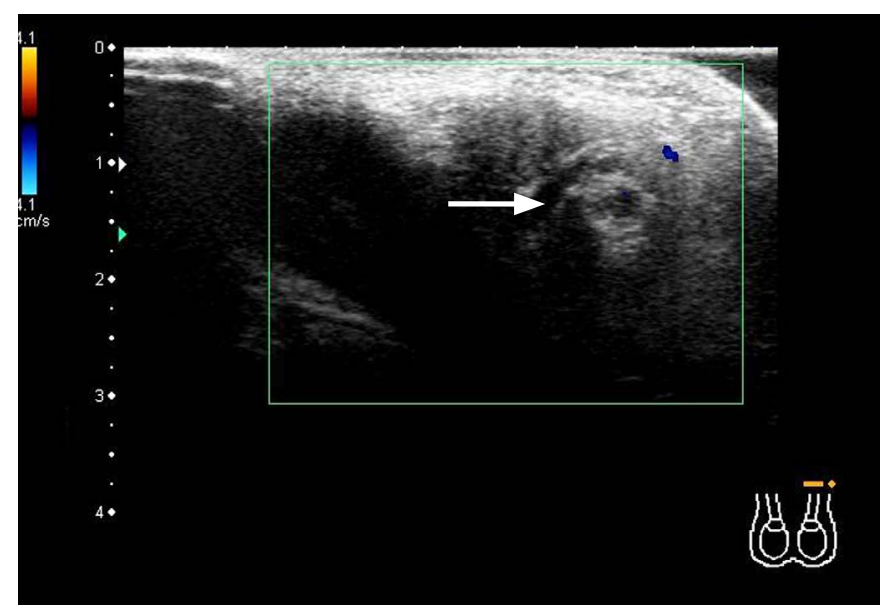

C

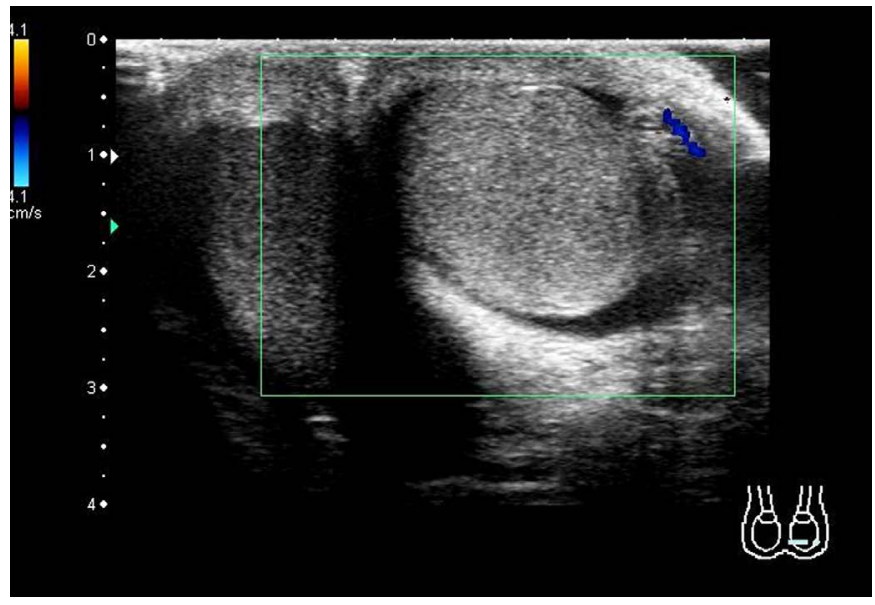

B

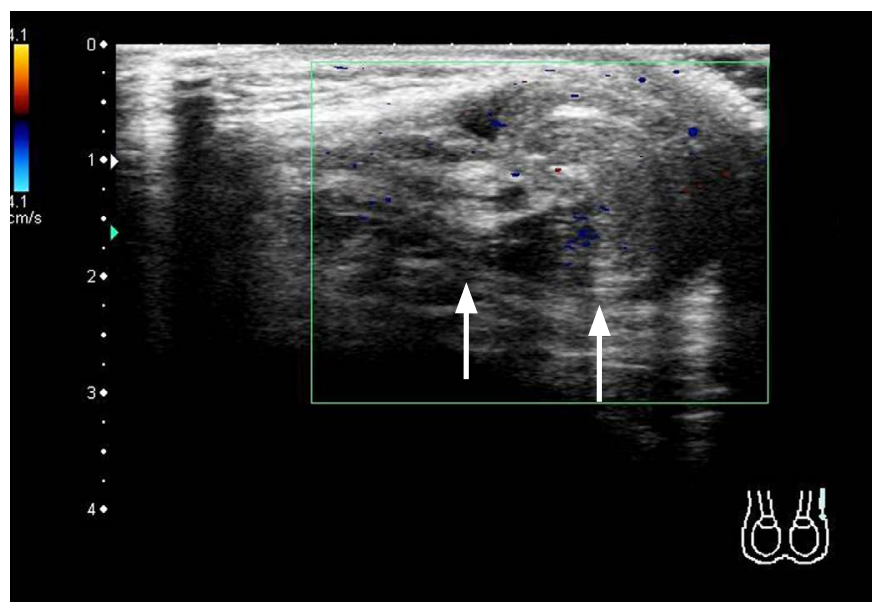

D

Fig. 1. Testicular torsion (intravaginal torsion) in a 12-year-old boy with sudden-onset left inguinal pain.

A, B. Compared with the normal right testis (A), the left testis is enlarged and heterogeneous, and its vascularity is lost (B). These findings strongly suggest testicular torsion. C, D. The twisted spermatic cord (arrows in C and D) is seen in the axial (C) and sagittal (D) images. This is the direct finding of testicular torsion. The operative findings showed a testis twisted by $360^{\circ}$ with discoloration. With surgical detorsion, the testis was preserved.

to intermittent torsion. A focal lack of enhancement helps to differentiate segmental infarction from tumors [26].

On elastography, stiffness increases in testicular torsion $[27,28]$, and in an animal model, stiffness changed according to time and severity [29]. Elastography may also offer information on spermatogenesis after testicular torsion. Higher stiffness values have been associated with qualitatively and quantitatively decreased spermatogenesis in an animal model [30].

\section{Extravaginal Torsion}

Extravaginal torsion occurs as a result of premature attachment of the tunica vaginalis to the scrotal wall. This leads to torsion of the tunica vaginalis, including its contents [31]. This mechanism is most common in the prenatal to neonatal period. Among cases of torsion in neonates, approximately $80 \%$ are prenatal, which are difficult to salvage, and approximately $20 \%$ are postnatal, which may be salvageable [32]. Although contralateral prophylactic orchiopexy is controversial [33], this may be indicated to avoid the risk of anorchia [32-34].

The sonographic findings of extravaginal torsion vary according to the stage [34]. In the acute stage, marked enlargement occurs, with heterogeneity and loss of vascularity (Fig. 2A, B). Other findings include linear hypoechoic striations (oriented radially from the mediastinum testis) (Fig. 2A), subtunica fluid, and hydrocele (Fig. 2A). In the later stages, shrinkage of the testis with increased echogenicity occurs (Fig. 2C, D). Knowledge of these changes is 


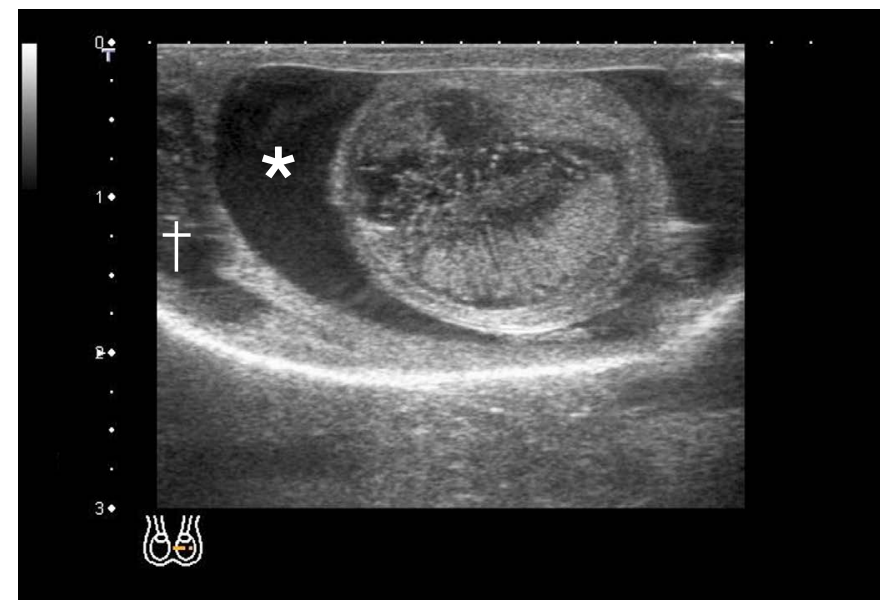

A

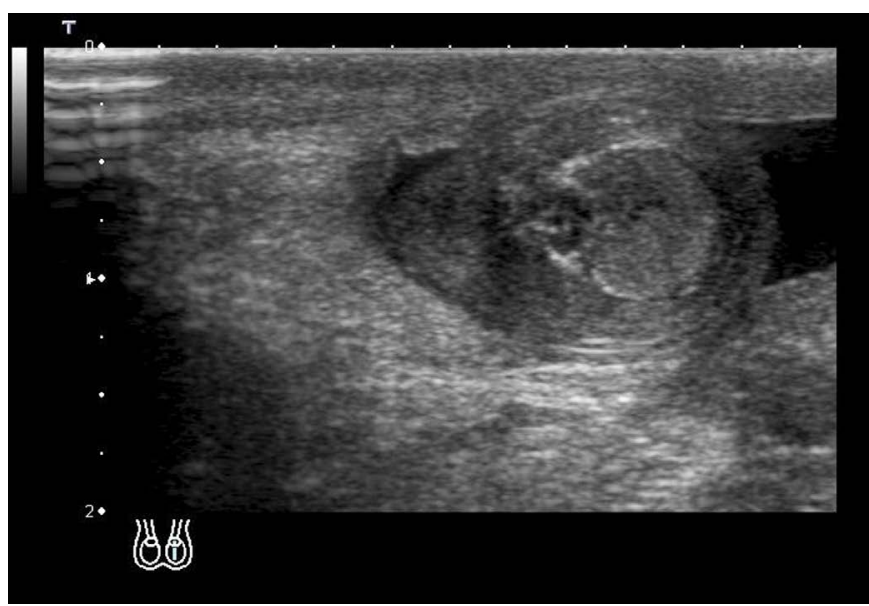

C

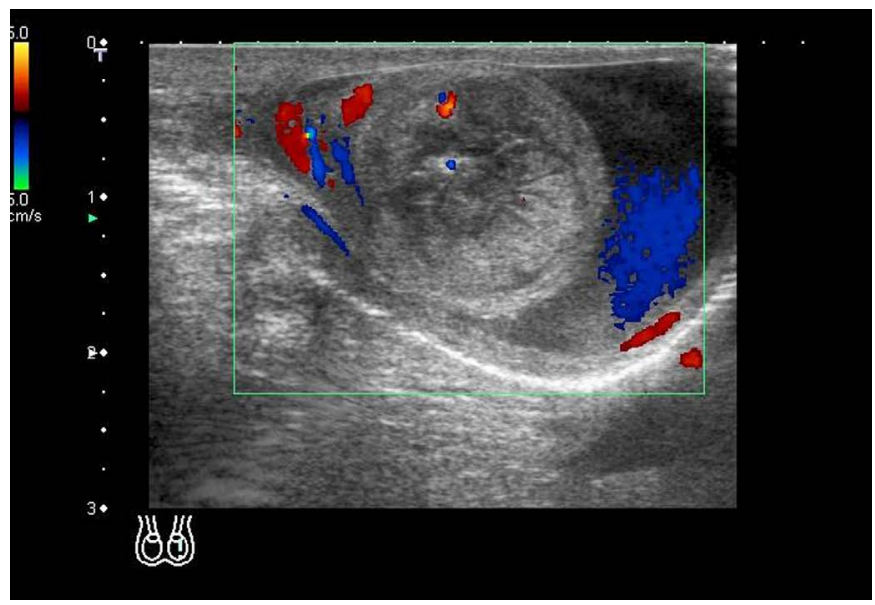

B

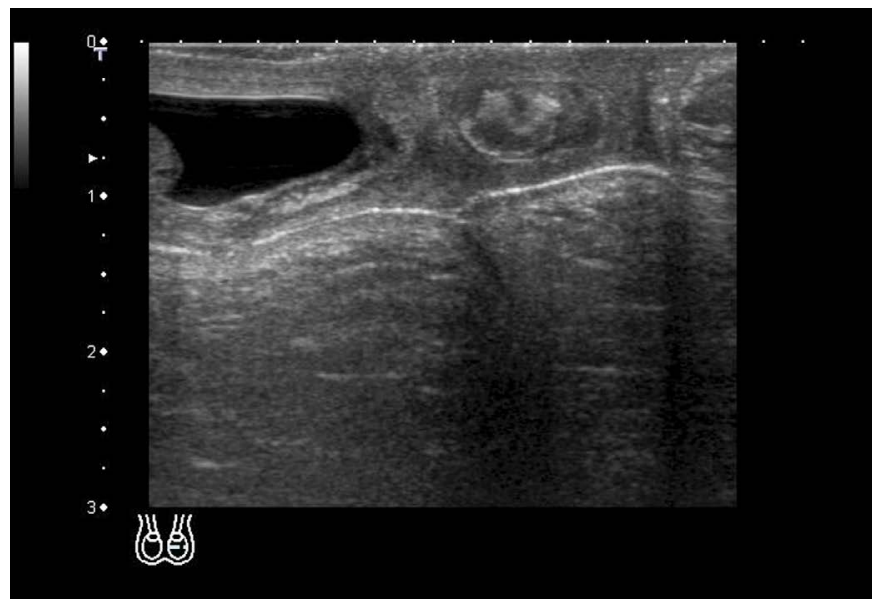

D

Fig. 2. Testicular torsion (extravaginal torsion) in a neonate with left scrotal swelling.

A, B. Ultrasonography on day 3 after birth (A), the enlarged testis shows heterogeneous echogenicity with linear hypoechoic striations, hydrocele (asterisk), and subtunica fluid (dagger) without vascularity in the testis on color Doppler image (B). These findings are characteristic of neonatal testicular torsion. C, D. On day 25 (C) and 2 months (D), ultrasonography shows shrinkage with increased echogenicity and calcifications (courtesy of Dr. M. Mikiko, National Center for Child Health and Development, Japan).

important because testicular flow is frequently not detectable even in a normal testis in neonates [35]. In this setting, elastography also may be useful to visualize the hardening of a necrotic testicle [27].

\section{Epididymitis}

Epididymitis is also a common cause of acute scrotum. Epididymitis is more common in adolescents; cases commonly involve sexually transmitted organisms, such as Neisseria gonorrhoeae and Chlamydia $[3,36]$. In infants, representative pathogens are Escherichia coli, Pseudomonas, and Aerobacter [36]. The underlying abnormalities in infants include an ectopic ureteral opening to the seminal vesicle, posterior urethral valves, and vesicourinary reflux
[37-40].

Although the need for imaging scrutiny regarding the underlying cause is controversial, some authors have suggested that patients with epididymitis, especially in infancy or after a second episode, should undergo an evaluation for underlying disease(s), via methods such as US and voiding cystourethrography $[37,38]$. This is because a correct diagnosis is needed, although epididymitis is typically treated conservatively.

Sonographic findings include swelling of the epididymis with decreased echogenicity (Fig. 3A, B) but may be heterogeneous, especially with hemorrhage. The head is commonly involved, and the entire epididymis may be involved in half of all cases (Fig. 3B). Severe swelling is frequently seen in patients with urogenital 


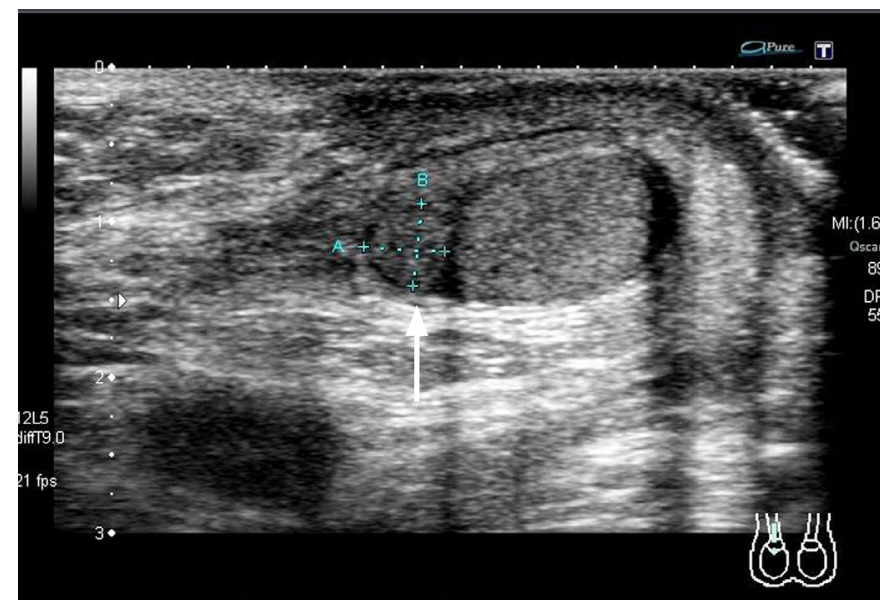

A

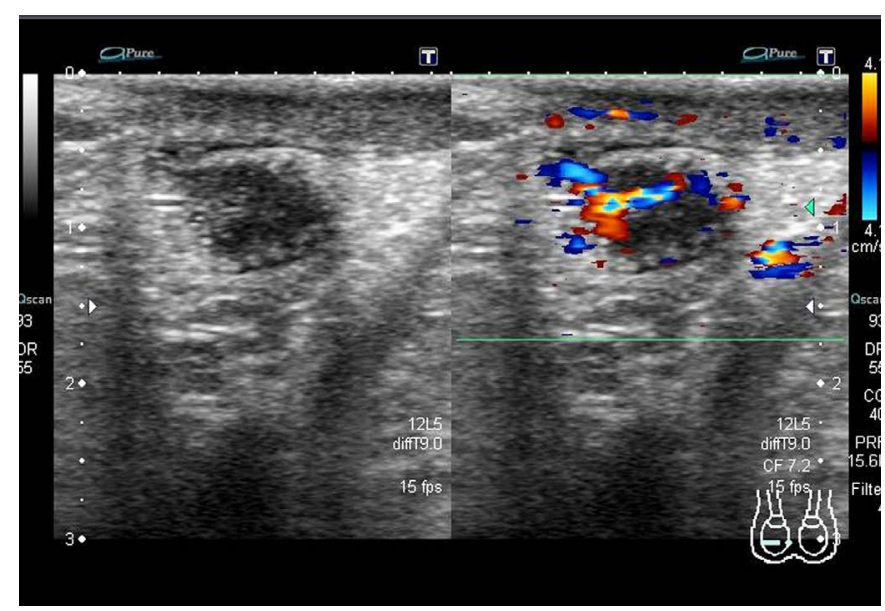

C

abnormalities [41]. Surrounding reactive changes, such as hydrocele and scrotal wall thickening, are also common. On color and power Doppler imaging, epididymal flow is increased (Fig. 3C) $[3,14,36]$, and the resistance index decreases to less than $0.5-0.7[3,42]$. The spread of inflammation causes orchitis (epididymo-orchitis) in 20\%$40 \%$ of cases, showing enlargement, heterogeneous echogenicity, and increased vascularity $[3,43]$. CEUS is essentially unnecessary, but there is a place for CEUS in assessing complications. In the case of abscess formation or testicular infarction secondary to epididymoorchitis, CEUS can offer additional information. These conditions are visualized as a non-enhanced area, and abscesses show strong peripheral enhancement [14]. In cases of focal orchitis, a neoplasm can be included in the differential diagnosis. Elastography can differentiate orchitis, with soft elasticity, from neoplasms, with hard elasticity [44].

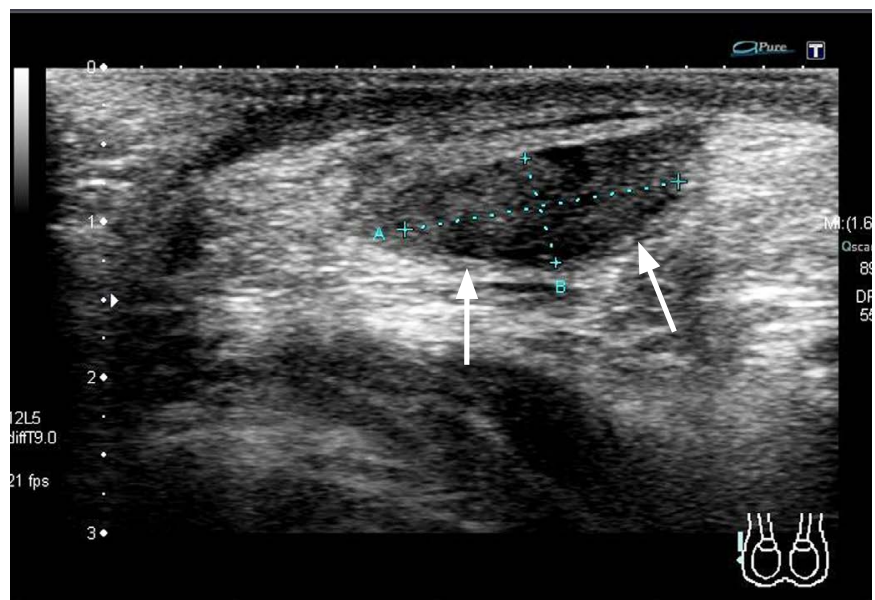

B

Fig. 3. Epididymitis in a 5-year-old boy with right scrotal pain. $A-C$. The epididymis shows marked enlargement in both the head (arrow in A) and body (arrows in B), and the epididymal vascularity is increased (C). Scrotal wall thickening is also seen $(A-C)$. The testicular vascularity was also slightly increased (not shown), suggesting secondary testitis.

\section{Testicular Appendage Torsion}

In most cases (approximately 91\%-95\%) of testicular appendage torsion, the testicular appendage is involved, and epididymal appendage torsion is rare [3]. This occurs frequently in boys aged 7-14 years. Appendage torsion is associated with the cold season [45]. On physical examination, the twisted appendage can be seen as a bluish nodule through the overlying skin. This "blue dot sign" is specific for appendage torsion, but its sensitivity is as low as $21 \%$ [43]. Thus, a sonographic diagnosis is important.

On gray-scale sonography, the testicular appendage is typically seen on the medial side of the upper pole of the testis (Fig. 4, Video clips 1,2). Depiction of the testicular appendage does not indicate torsion because the appendage is a normal structure. A twisted appendage was previously thought to be typically hyperechoic $[46,47]$, but a recent study suggested that echogenicity changes with time [48]. A twisted appendage is initially hypoechoic but may 


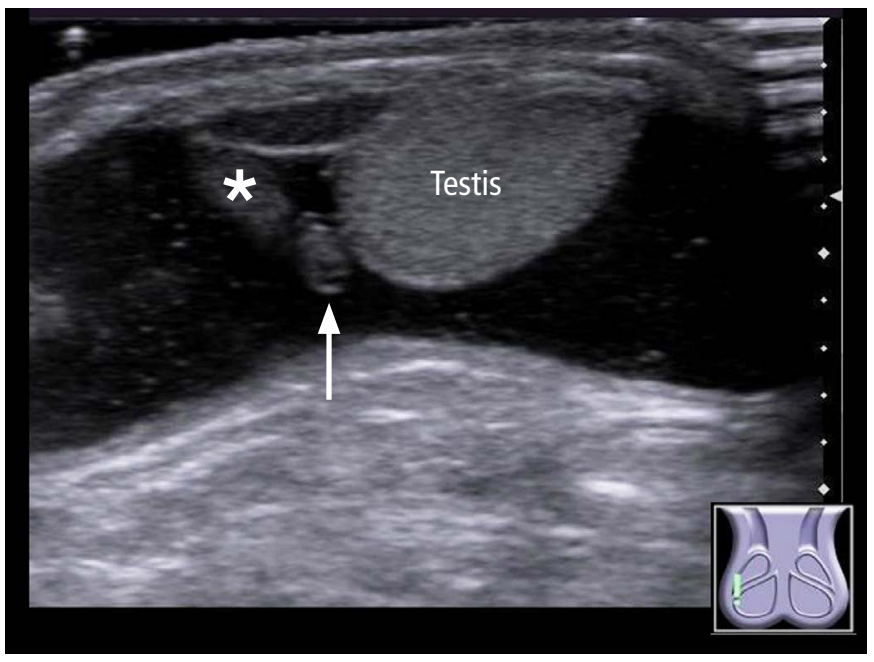

A

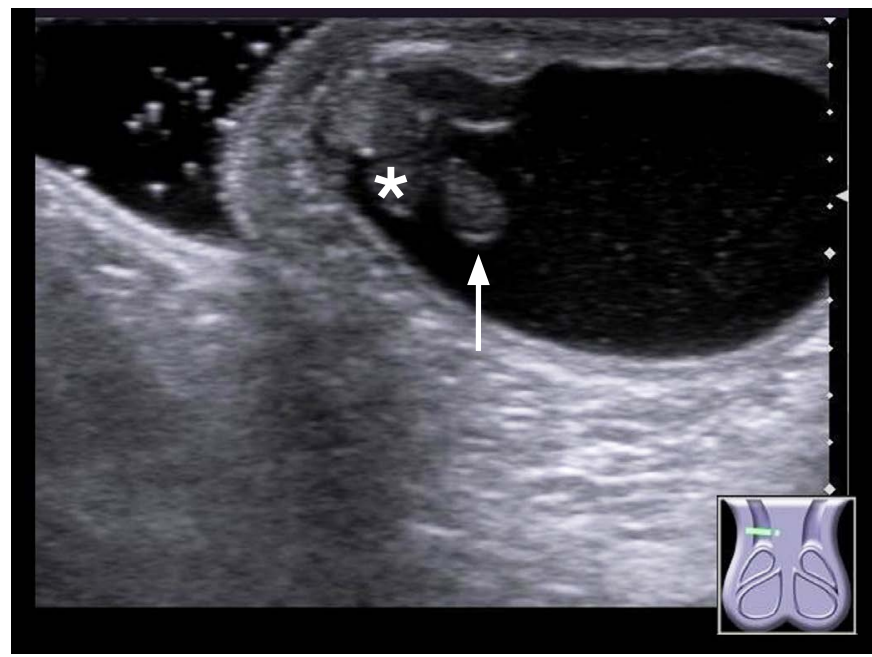

B

Fig. 4. Normal testicular appendage in a 3-year-old boy with right hydrocele testis.

A. Sagittal image shows the appendage (arrow) at the groove between the epididymis (asterisk) and testis. B. An axial image at the level of the lower edge of epididymal head (asterisk) shows the appendage (arrow) on the medial side of the epididymis (asterisk).

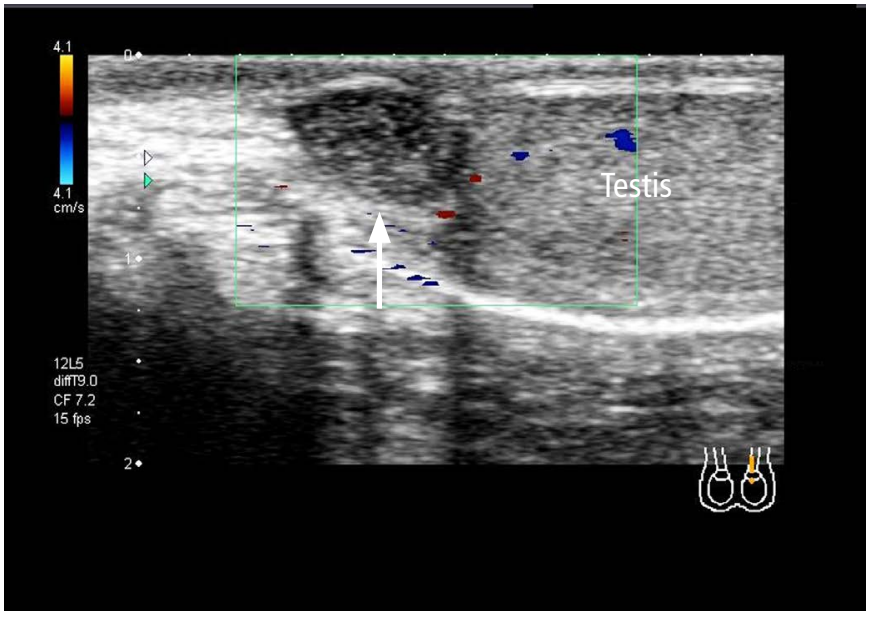

A

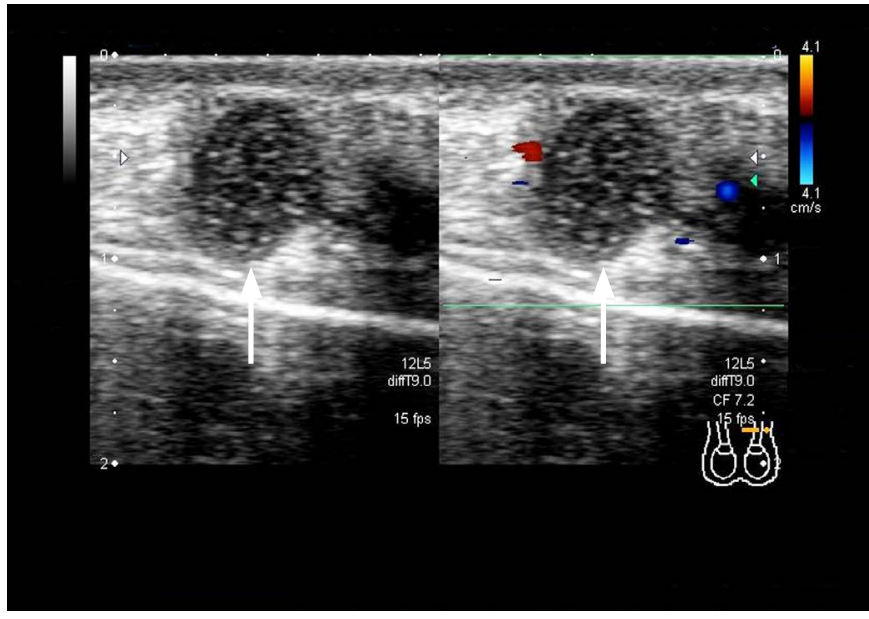

B

Fig. 5. Testicular appendage torsion in a 12-year-old boy with left scrotal and back pain.

A, B. Color Doppler images were obtained in sagittal (A), and axial view (B). The testicular appendage (arrows in A and B), located at the upper pole of the testis, was swollen to $>8 \mathrm{~mm}$. Vascularity was lost in the appendage (arrows in A and B).

be hyperechoic after $>24$ hours [48]. A hypoechoic appendage usually has a salt-and-pepper appearance, with multiple bright spots and septa $[48,49]$. Twisted appendages show swelling (ranging in size from 3 to $17 \mathrm{~mm}$ ) (Fig. 5A) [46,47], compared with normal appendages (1-7 mm) (Fig. 4) [47,50]. Some have proposed a criterion of $5.6 \mathrm{~mm}$ as suggestive of testicular appendage torsion [47]. Additional findings include hydrocele testis and epididymal enlargement [46], which may potentially lead to the misdiagnosis of epididymitis. Appendage torsion is treated conservatively, which is also true for epididymitis. However, in the case of appendage torsion, manual reduction is also applied under sonographic monitoring $[48,49]$. In the case of epididymitis, scrutiny regarding the underlying cause may be necessary. Thus, an accurate diagnosis remains important. The success rate of manual reduction varies according to echogenicity: $91 \%$ for hypoechoic, $75 \%$ for isoechoic, and $50 \%$ for hyperechoic appendages [48].

On color Doppler images, no vascular signal is seen in a twisted appendage (Fig. 5B) $[43,47,48,50]$. After reduction, appendages 
show increased vascularity and decreased size [48].

\section{Testicular Trauma}

Testicular trauma causes hemorrhage and infarction of the parenchyma, ultimately leading to necrosis. In serious cases, disruption of the tunica albuginea can occur, also known as testicular rupture, accompanied by parenchymal protrusion. This is an indication for urgent surgery, and early surgical intervention improves long-term testicular function [14]. Sonographic findings include changes in echogenicity due to hemorrhage and ischemia, and irregular testicular contours and/or discontinuity of the tunica albuginea suggest testicular rupture (Fig. $6 \mathrm{~A}$ ). Although tunica albuginea breach per se was visualized in only $50 \%$ of cases of testicular rupture in one study, US showed a sensitivity of $100 \%$ and a specificity of $65 \%$ for testicular rupture [51].

CEUS has been found to show no significant defect in enhancement in cases of minor trauma, and weak, inhomogeneous, or patchy enhancement for severely fractured testicles. Hematomas have been found to show no enhancement [14]. Magnetic resonance imaging may be an alternative modality when the use of US results in an inconclusive diagnosis [52].

\section{Acute Idiopathic Scrotal Edema}

AISE is a self-limiting disease, commonly seen in children under 10 years of age (mean, 6 years) [53]. Its etiology is unknown, but infection, allergic reaction, and angioedema are presumed [53]. AISE shows spontaneous regression, but recurrence is also seen, in up to $21 \%$ of cases [53]. The typical presentation is scrotal erythema and edema without tenderness [53]. Erythema and swelling can extend into the perineal and inguinal region in approximately $50 \%$ of cases. The rate of unilateral versus bilateral presentation varies across reports; the rate of bilateral presentation is $10 \%-100 \%[53,54]$. Patients are usually afebrile, but systemic fever can be seen in up to one-third of cases [53]. Laboratory examinations show normal ranges, except for the possible presence of eosinophilia, supporting the theory of an allergic etiology [53]. Sonographic findings include scrotal wall thickening with a heterogeneous striated and edematous appearance (Fig. 7A, B) and hypervascularity (Fig. 7C) (called the fountain sign in bilateral cases), and possible inguinal lymphadenopathy [53-55]. However, these findings are non-specific, and ruling out other diseases is important. In AISE, morphology and vascularity are normal in the testis, epididymis, and spermatid cord $[43,53,55]$.

\section{Ovarian Torsion}

Ovarian torsion refers to a twisted vascular pedicle, which leads to vascular insult, resulting in ovarian ischemia and ultimately necrosis. Autoamputation can occur, especially in neonatal torsion [56]. This disastrous condition is also important in the pediatric field. Salvage rates in pediatric series vary across reports, ranging from only $0 \%-$ $27 \%$ in one report [57] to a majority of cases in another [58].

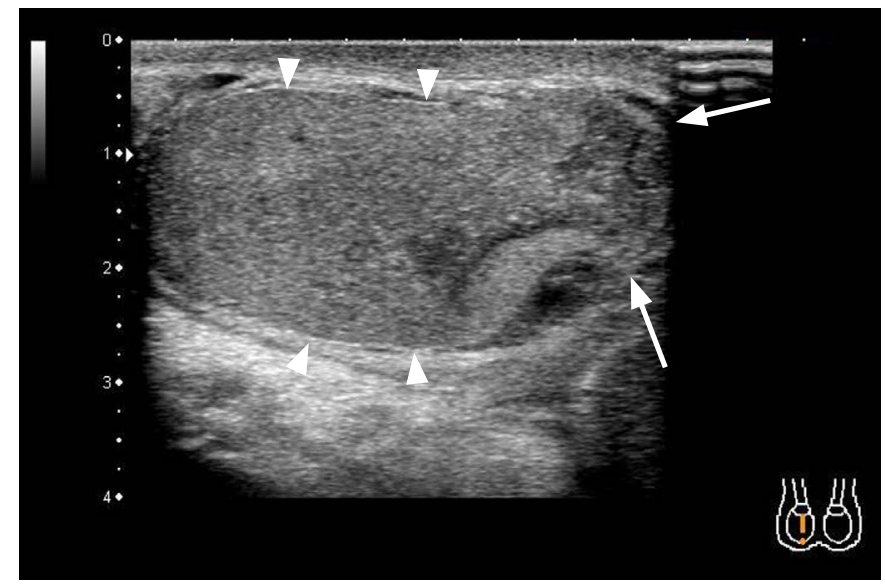

A

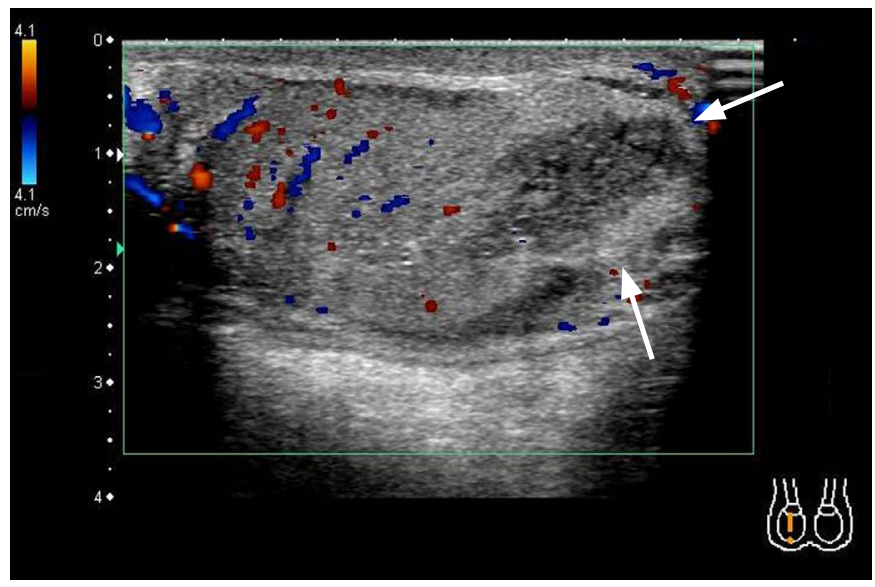

B

Fig. 6. Testicular rupture in a 13-year-old boy hit in the right testis by a foul ball on the first bounce.

A. The continuity of the tunica albuginea (arrowheads) is obscure at the lower pole, and the heterogeneous testicular tissue had prolapsed (arrows). B. In a color Doppler image, the prolapsed tissue had lost its vascularity (arrows). Laceration of the tunica albuginea was confirmed; it was reconstructed surgically, and prolapsed necrotic testicular tissue was resected (courtesy of Dr. M. Mikiko, National Center for Child Health and Development, Japan). 


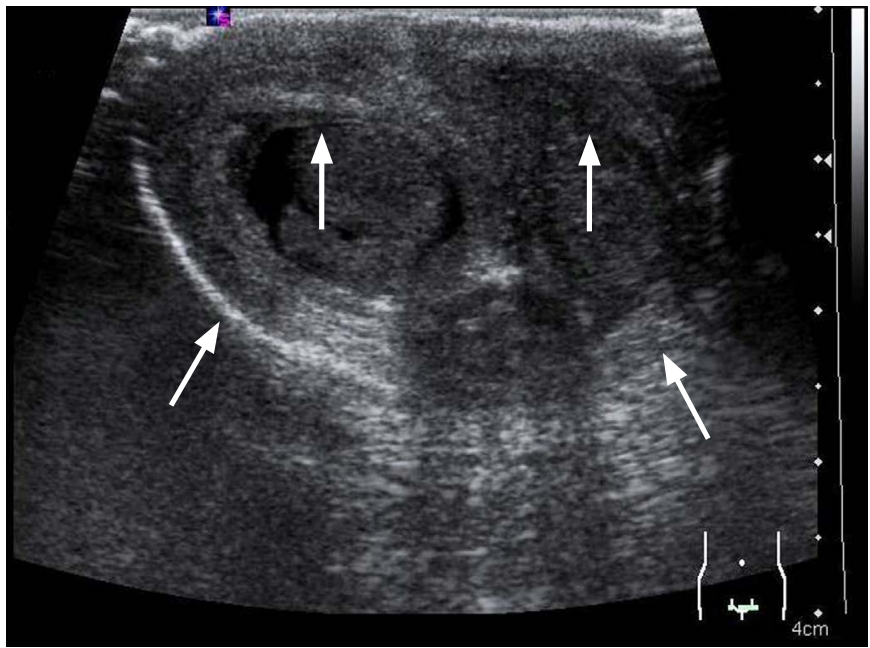

A

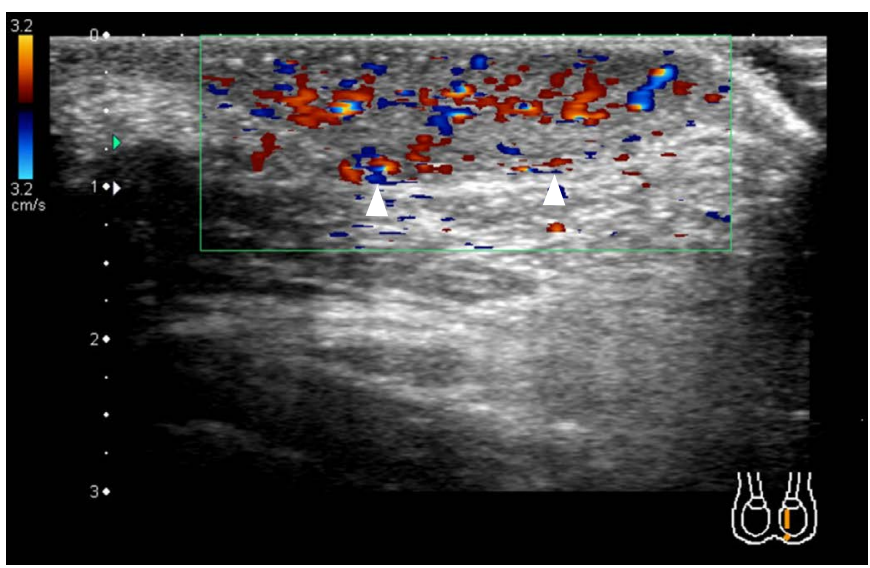

C

There appears to be significant individual variation in the time to infarction, and there is no clear golden time for surgery, in contrast to testicular torsion [57]. The age distribution is bimodal, with the two peaks occurring in infants and adolescents [59]. Ovarian torsion is much more common on the right side because of the smaller free pelvic space on the left side due to the sigmoid colon [60]. Torsion usually occurs in association with an ovarian mass. The mass is usually benign, typically an ovarian cyst or teratoma; the reported malignancy rate was only $1.8 \%$ in pediatric cases of ovarian torsion [61].

The most common sonographic findings are enlargement and heterogeneity [58]. A mass of $>5 \mathrm{~cm}$ is $83 \%$ sensitive for ovarian torsion [59], although this finding is not specific. Ovarian hemorrhage is rare in prepubertal children because endometriosis and tubo-ovarian abscess are exceedingly rare. Thus, a hemorrhagic ovarian cyst suggests ovarian torsion [58], although false-positives have been reported [62].

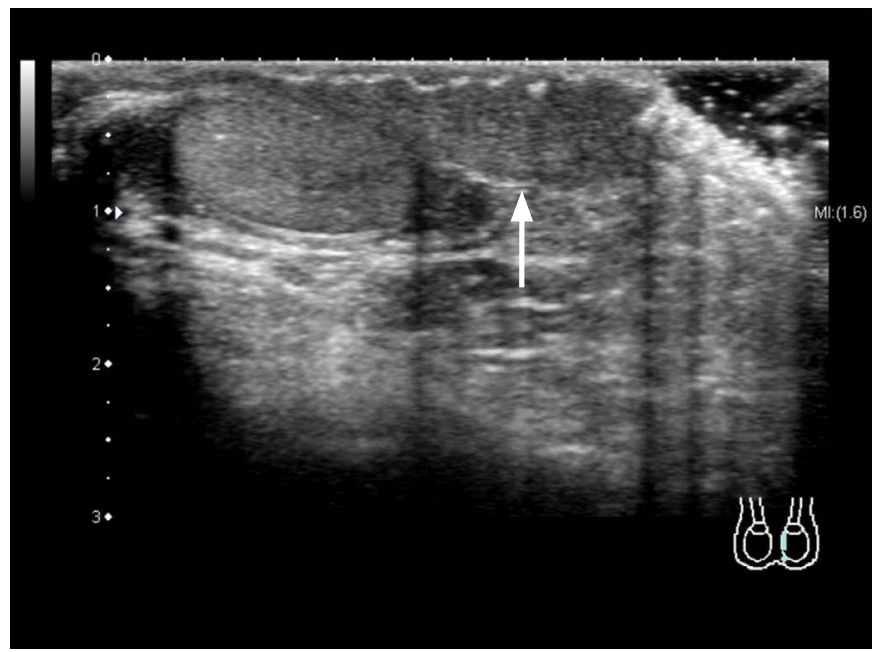

B

Fig. 7. Two cases of acute idiopathic scrotal edema: a neonate with scrotal swelling $(A)$ and a 6 -year-old boy with scrotal pain $(B$, C).

A. The bilateral scrotal walls are markedly thickened (arrows). B, C. The scrotal wall is markedly thickened (arrow in B) with increased vascularity (arrowheads in C). Symptoms improved spontaneously in both patients.

In addition to cystic ovarian masses causing ovarian torsion, intraovarian cysts should be evaluated carefully. Peripherally located cysts (Fig. 8A), which are not true cysts and may be attributable to the transudation of fluid due to congestion, have a relatively high specificity of $74 \%[62,63]$. Ovarian enlargement with multiple peripheral cysts can show a high positive predictive value (87.5\%) and specificity (93.3\%) [63]. The follicular ring sign, or perifollicular hyperechoic rim, has also been reported to have a high specificity $(80 \%)$, and is seen starting in the early stage of torsion [64]. This sign should be differentiated carefully from the acoustic shadow artifact of normal follicles in terms of the following features: it is seen concentrically around the follicles and exhibits a perceptible thickness (1-2 mm) [64]. A transvaginal scan is recommended, if available, but this sign can also be detected on a transabdominal scan [64]. The intrafollicular fluid-debris level is an additional follicular feature with a high specificity (85\%) [65].

Other classical signs include ovarian edema, abnormal ovarian 


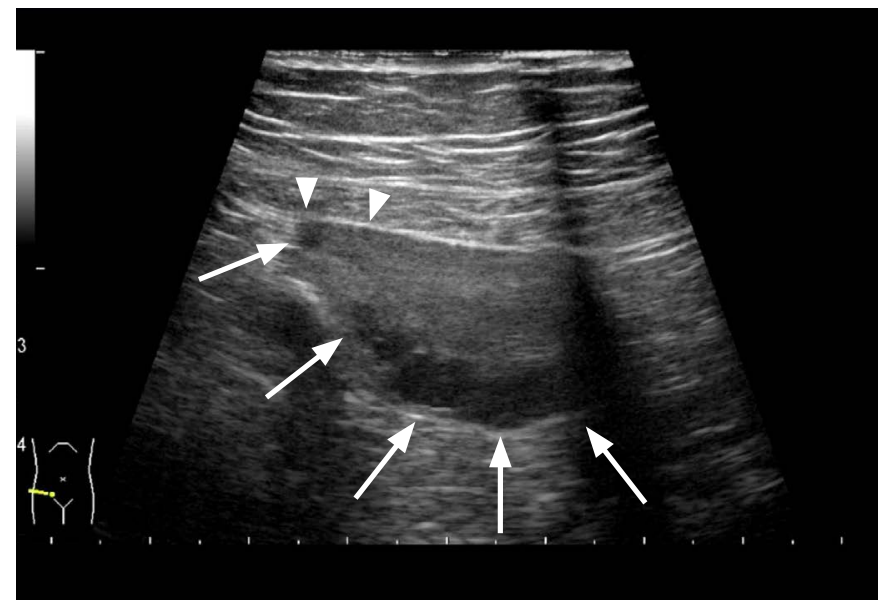

A

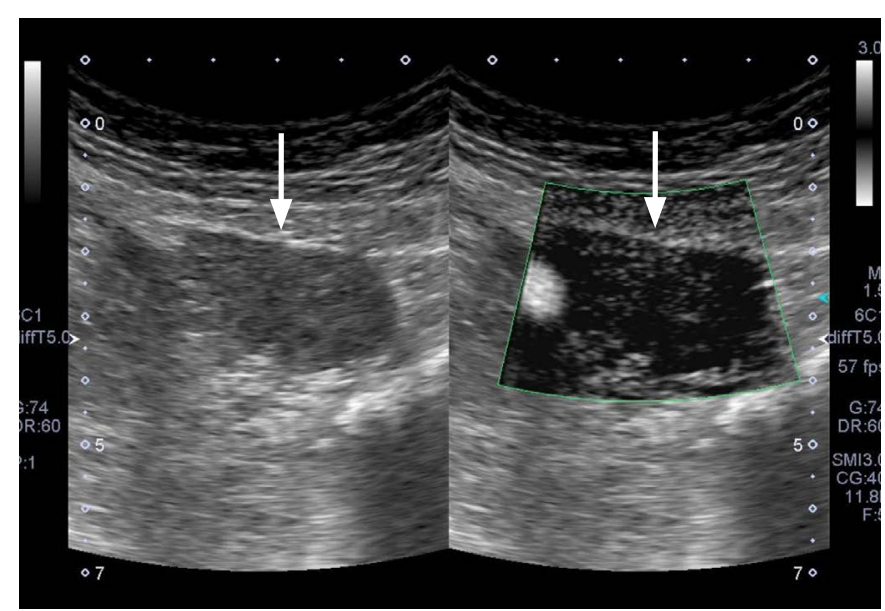

C

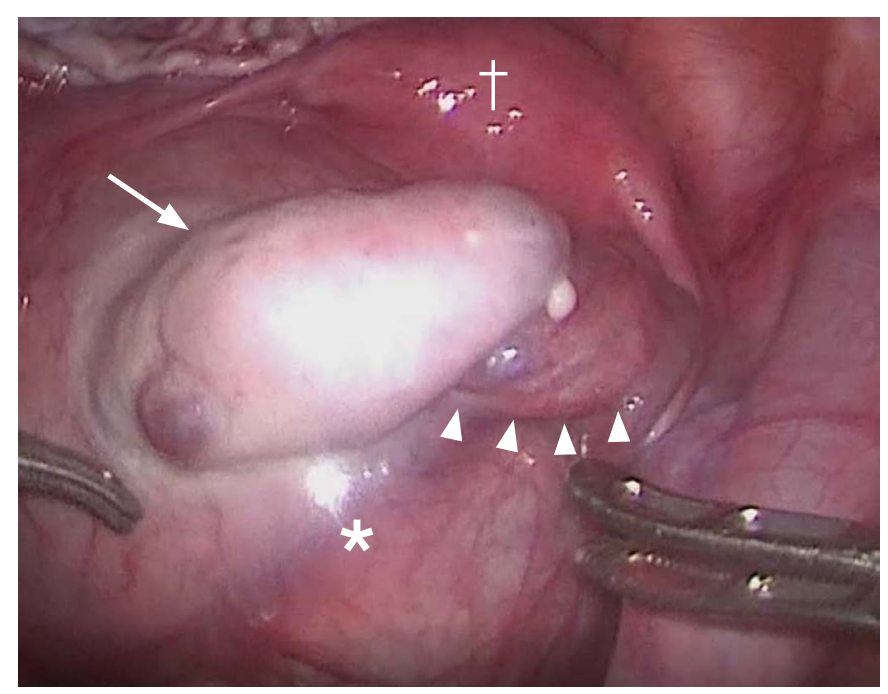

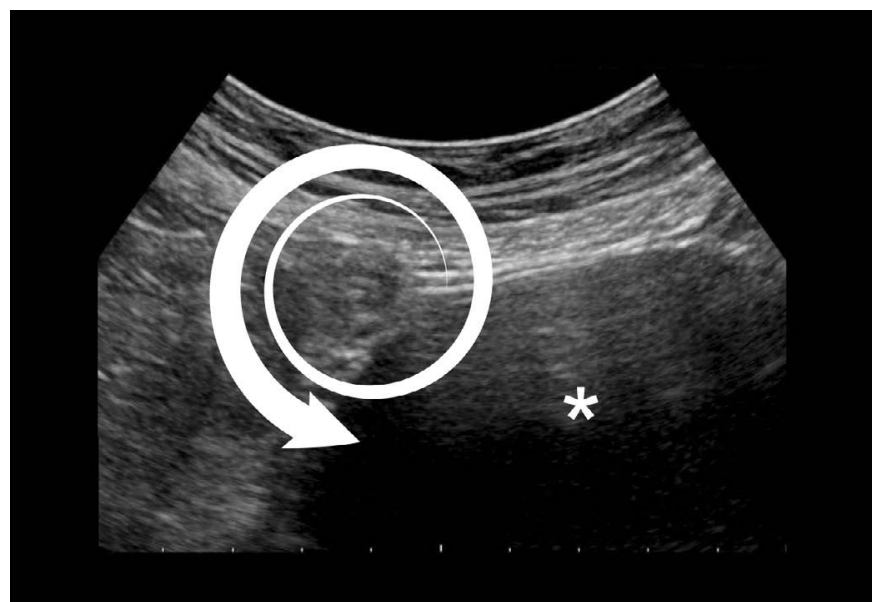

B

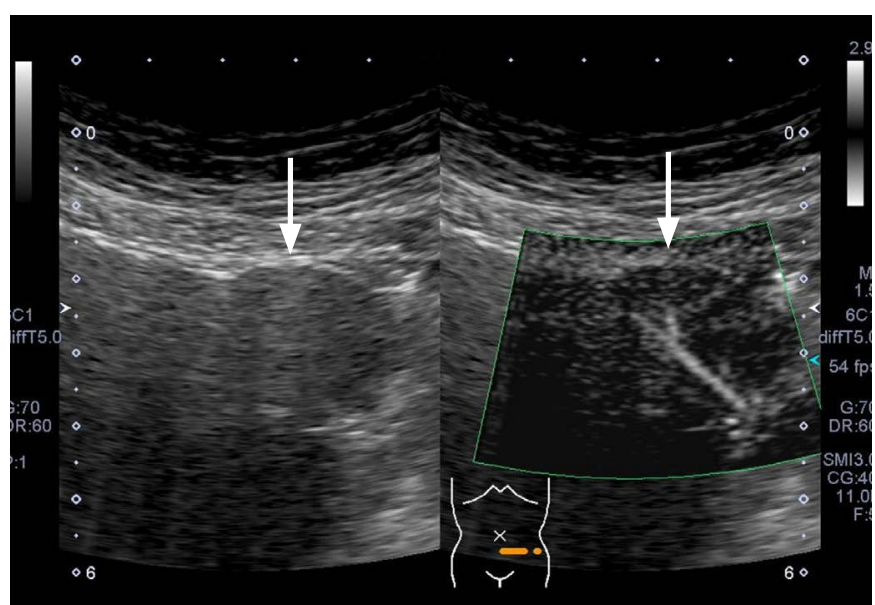

D

Fig. 8. Ovarian torsion in a 16-year-old girl.

A. The affected ovary shows multiple peripherally located cysts (arrows). Note that the edge of the ovary is stretched (arrowheads) due to the torsion. B. The ovarian pedicle is twisted (in the center of spiral arrow) and can be seen as a whirlpool sign (Video clip 3). A large paraovarian cyst (the cause of torsion) is also seen (asterisk). C, D. The vascularity in the affected ovary is obscure (arrows in C) compared to the normal ovary (arrows in D) on superb monochrome microvascular imaging. E. An operative image shows the twisted pedicle (arrowheads) of the ovary (arrow). The asterisk indicates the transparent paraovarian cyst, and the dagger indicates the uterus. 
position, free fluid in the pouch of Douglas, and the absence of ovarian vascularity (Fig. 8C) $[58,63,66-70]$. Venous flow is obstructed first, and arterial flow shows a "spiky" pattern. Both arterial and venous flow are then lost in the advanced stages [70]. The ability to make a diagnosis based on ovarian vascularity has considerable variation, with a positive predictive value of 19\%-94\% and a negative predictive value of $46 \%-100 \%[68,69,71]$. There seem to be many factors affecting accuracy: dual supply from the uterine and ovarian arteries to the ovary, incomplete or intermittent torsion, the small size of vessels and low flow in children, and the deep location of the ovary. Moreover, the selected slice may not correctly reflect the vascularity of the entire ovary [72]. Recently, 3-dimensional assessment, which allows the evaluation of the whole ovary with quantitative vascular assessment, has been applied to ovarian torsion in adults [72-74], although this was performed with a transvaginal approach. Another solution could be CEUS. An animal study showed that the administration of contrast material enhanced the visualization of ovarian flow [75], and a case report showed decreased flow in a twisted ovary in a 6-year-old girl [76].

The whirlpool sign and a twisted pedicle have been reported to be useful and diagnostic (Fig. 8B, Video clip 3) $[66,77,78]$. This is a direct finding of torsion; however, the utility of the whirlpool sign has not been fully evaluated in pediatric series, where a transvaginal approach is not applicable [58]. For example, Lee et al. [78] showed $87 \%$ accuracy in an adult series, but they used a transvaginal probe in 47 patients, with the exception of four patients who were virgins or pregnant. They also stated that it was difficult to identify the whirlpool sign by a transabdominal approach [78]. This limitation seems to have resulted in the claim by some authors that US is not reliable in the diagnosis or exclusion of ovarian torsion in the pediatric population [59], although other authors insist on the utility of the whirlpool sign with a transabdominal approach [77]. The US diagnosis of ovarian torsion is not straightforward, and it is affected greatly by the operator $(60 \%-100 \%)$ [69]. Thus, other modalities should be used in equivocal cases.

Neonatal ovarian torsion should be considered separately because this condition usually occurs antenatally. Of patients with neonatal ovarian torsion, $91 \%$ had ovarian cysts on prenatal US [79]. US shows complex cystic masses, suggesting hemorrhage, with signs such as multi-septation, echogenic debris, and/or fluid-fluid levels (Fig. 9) $[67,79]$. Calcification can also be seen in some cases [79]. There are several pitfalls in the diagnosis of neonatal torsion. Half of the ovaries with torsion may show an extrapelvic location and could be misdiagnosed as appendicitis or as an abscess [67]. Moreover, a thickened wall can show an echogenic inner rim, mimicking duplication cysts (Fig. 9A) [79].

Another special condition of ovarian torsion is seen in ovarian hernia [80-84]. Ovarian hernia is commonly seen in infants, and the incidence of irreducible ovaries is $6 \%-7 \%$ for inguinal hernias in girls [83]. As the ovarian vascular pedicle is narrowed in the internal ring, the size of the ovary is relatively greater than the pedicle. This causes a predisposition for the ovary to twist [84]. Ovarian hernia

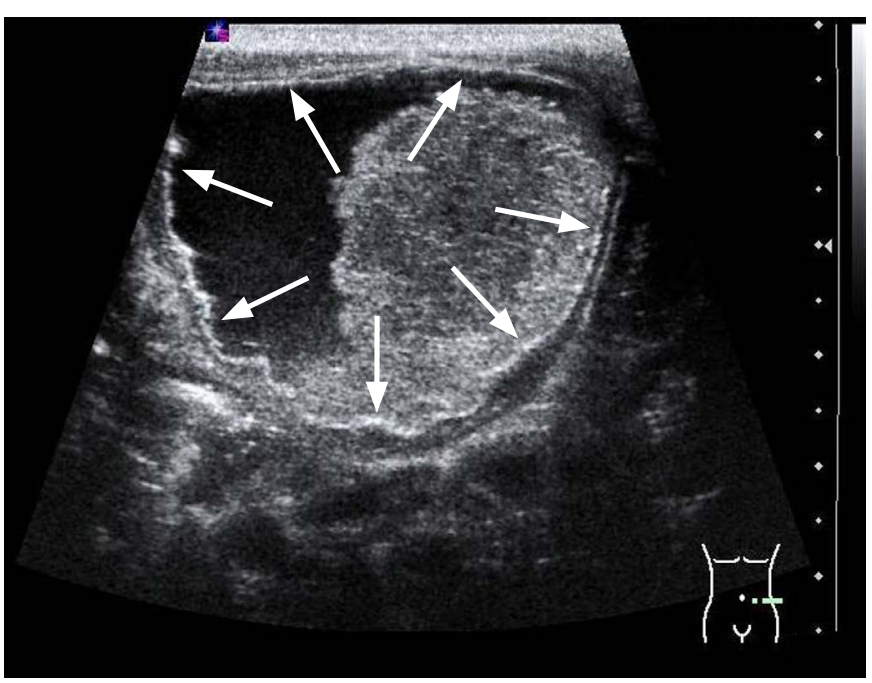

A

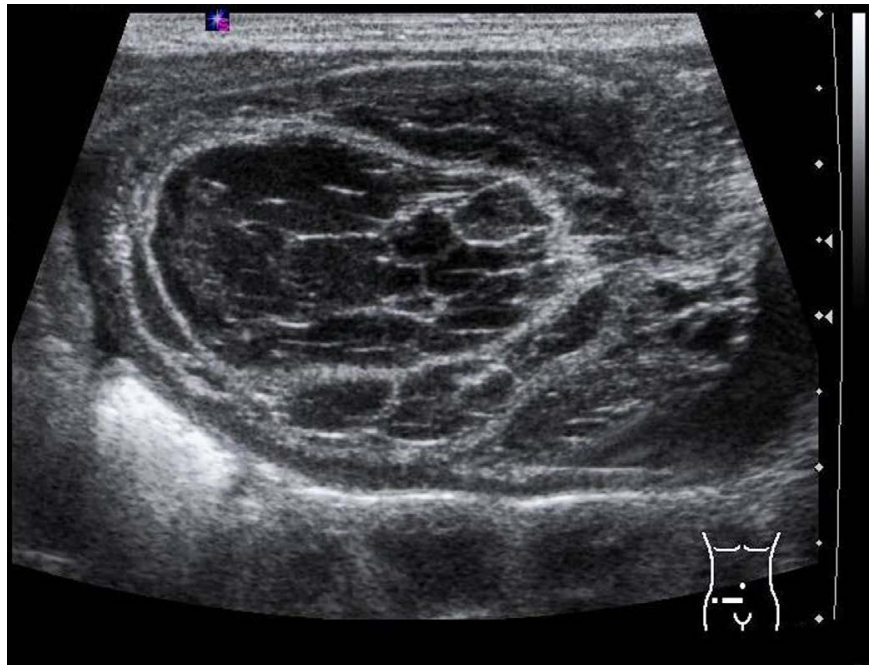

B

Fig. 9. Two cases of ovarian torsion in neonates.

A. A cystic mass is seen in a day 0 baby. The cyst contains debris. The cyst wall shows thickening and an echogenic inner rim (arrows), which mimics a duplication cyst. B. A cystic mass is seen in a day 1 baby. The cyst wall is thickened, and the cyst shows multi-septation internally. This mimics a lymphatic malformation (lymphangioma). 
has a risk of torsion, and it is necessary to evaluate the possibility of torsion, including vascularity. If torsion exists, this should be treated as an emergency [84]. Unlike deep in the pelvis, US with a high-frequency linear probe is useful in evaluating inguinal hernia. Ovarian hernia is readily recognized as an oval mass with small cysts on US [80]. The sonographic findings of twisted ovarian hernia include multiple cysts, ovarian enlargement, and heterogeneous hyperechogenicity [82]. A twisted pedicle and decreased vascularity can also be seen (Fig. 10).

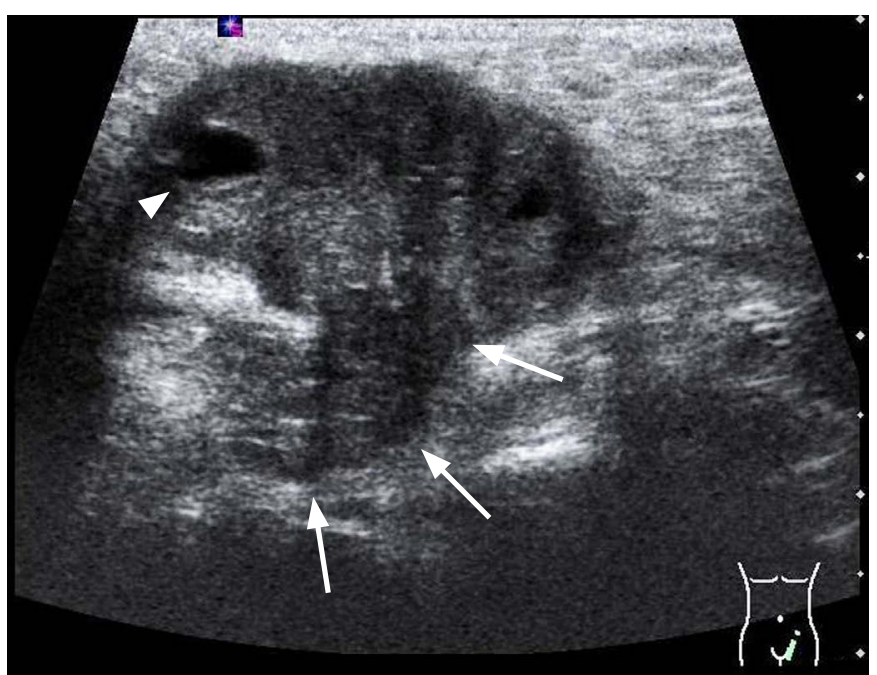

A

\section{Emergencies due to Associations of Urogenital Anomalies}

If atresia of the uterine cervix, vagina, or hymen is present, menstrual blood discharge is obstructed at menarche, leading to hematometra, also called menstrual molimina. Usually, atresia goes unnoticed until abdominal pain occurs. Thus, radiologists sometimes encounter cases of hematometra presenting with acute abdominal pain. US shows uterine dilatation with echogenic fluid (Fig. 11), with or without cervical dilatation, according to the area of atresia [85].

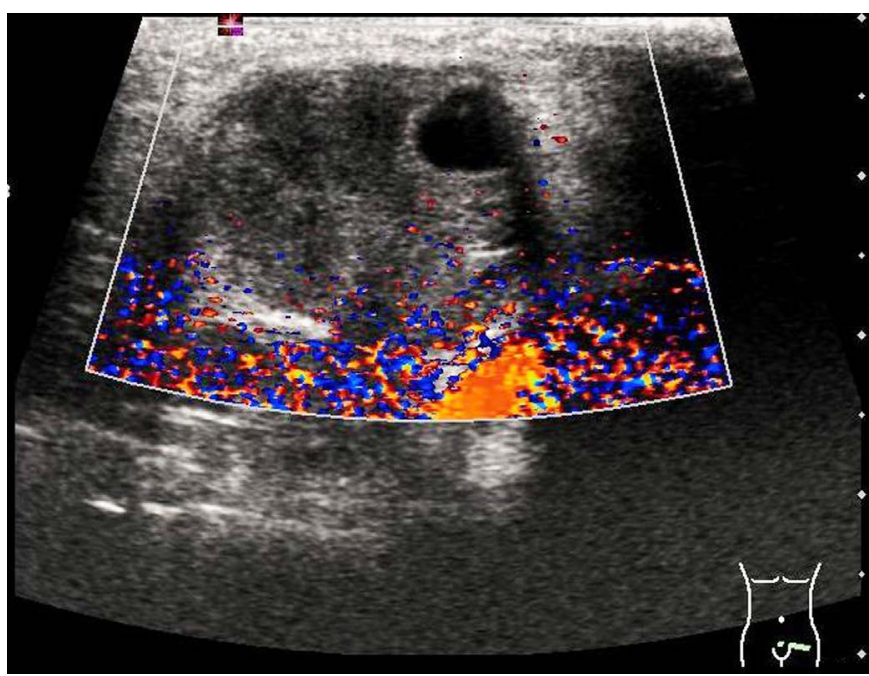

B

Fig. 10. Ovarian hernia with torsion in an 8-month-old girl with left inguinal swelling.

A, B. The mass contains multiple cysts inside of it, suggesting that is an ovary. Twisting of the ovarian pedicle is seen (arrows in A), and vascularity is not detectable on a color Doppler image (B). The follicle contains debris (arrowhead in A).

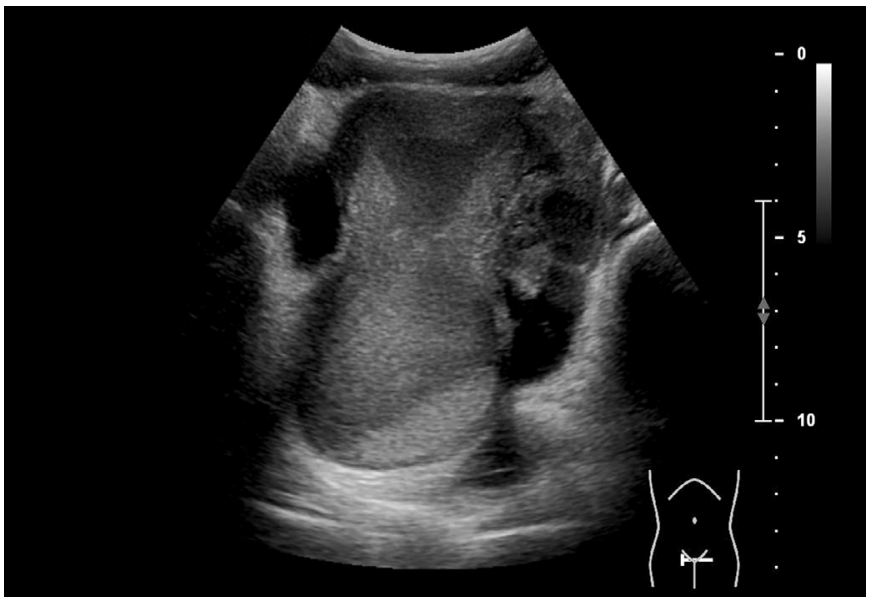

A

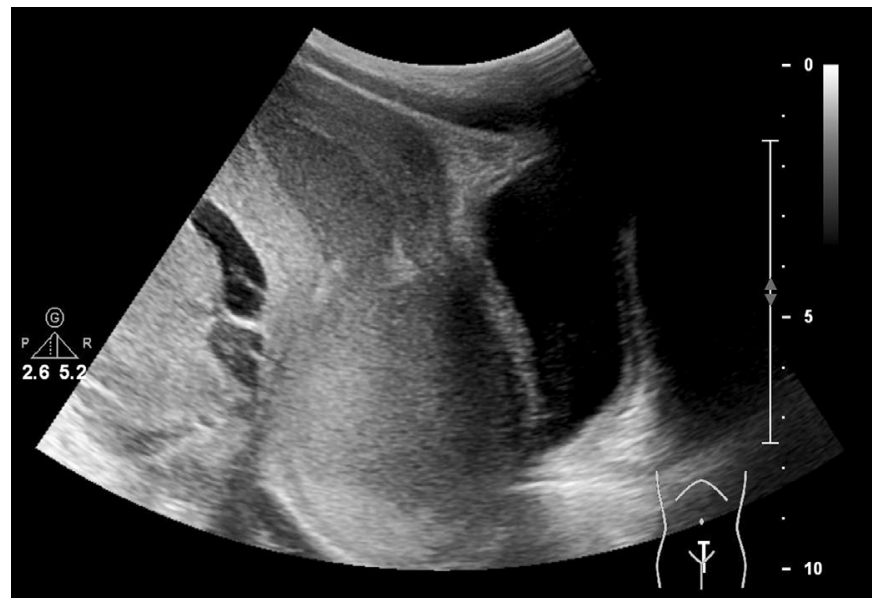

B

Fig. 11. Hematometra in a 10-year-old girl before menarche, with recurrent abdominal pain over a few months (menstrual molimina). Axial (A) and sagittal (B) images show a dilated uterine cavity with echogenic fluid, with fluid levels suggesting hydrometra with uterine cervical atresia. Note the intra-abdominal hematoma with complex echogenicity. 
Fluid-fluid levels can be seen in some cases (Fig. 11).

Uterine or vaginal atresia with Müllerian duct anomalies is frequently accompanied by renal anomalies. In particular, renal aplasia is highly predictive of an ipsilateral obstructive Müllerian anomaly, with this association found in more than $50 \%$ of cases [86]. The combination of unilateral renal aplasia, a duplicated uterus, and vaginal occlusion with Gartner pseudocyst was initially reported by Herlyn and Werner in 1971 (Herlyn-Werner syndrome) [87]. Wunderlich [88] reported the combination of renal agenesis and hemicervical atresia in 1976 (Wunderlich syndrome). In 1979, these cases were reported as Herlyn-Werner and Wunderlich syndromes [89]. These concepts are often combined as Herlyn-WernerWunderlich syndrome, although the claim has been made that such a syndrome does not exist [90]. Recently, the term obstructed hemivagina and ipsilateral renal anomaly has also been commonly used because this concept incorporates all kinds of uterine anomalies other than a duplicated uterus. Thus, the definition of syndromes is complex; however, the key fact is quite simple: there is an association of urogenital anomalies on the same side.

The typical presentation of these syndromes is abdominal pain at menarche. This diagnosis is relatively easy for pediatric radiologists familiar with these anomalies. However, these cases are sometimes initially misdiagnosed, probably because it is not possible to predict whether patients will initially visit emergency rooms, physicians, surgeons, or pediatricians. Moreover, radiologists may not always be involved. Thus, these patients should be noted before symptoms

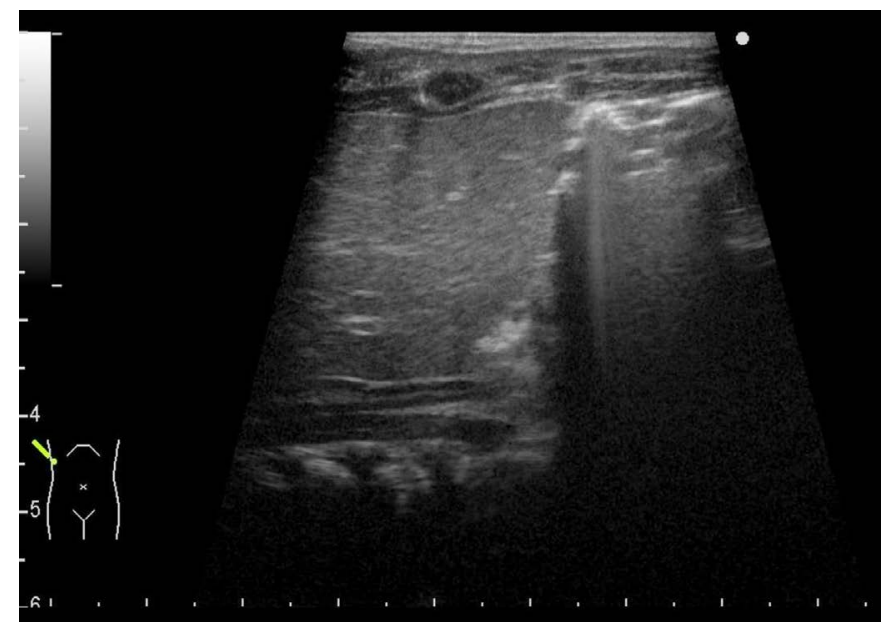

A

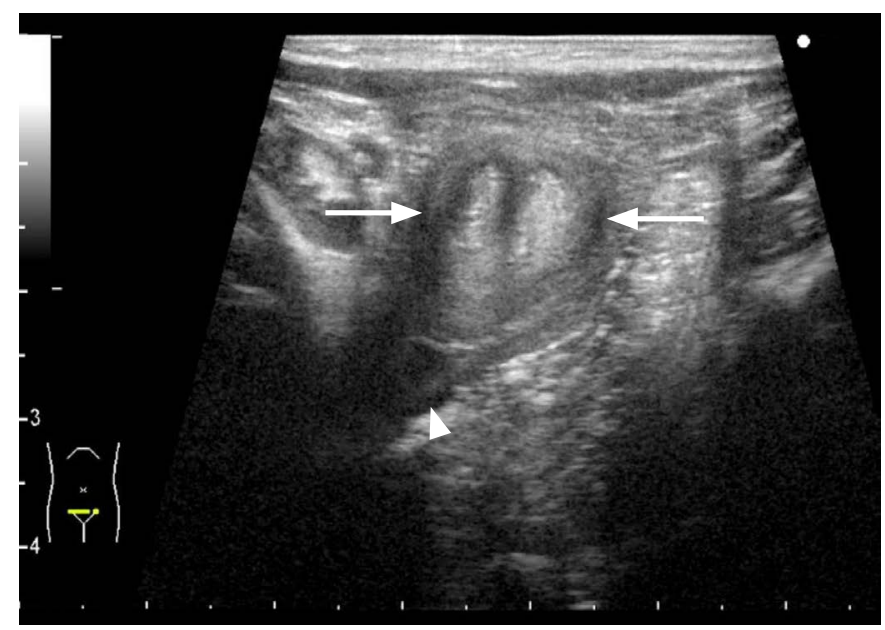

C

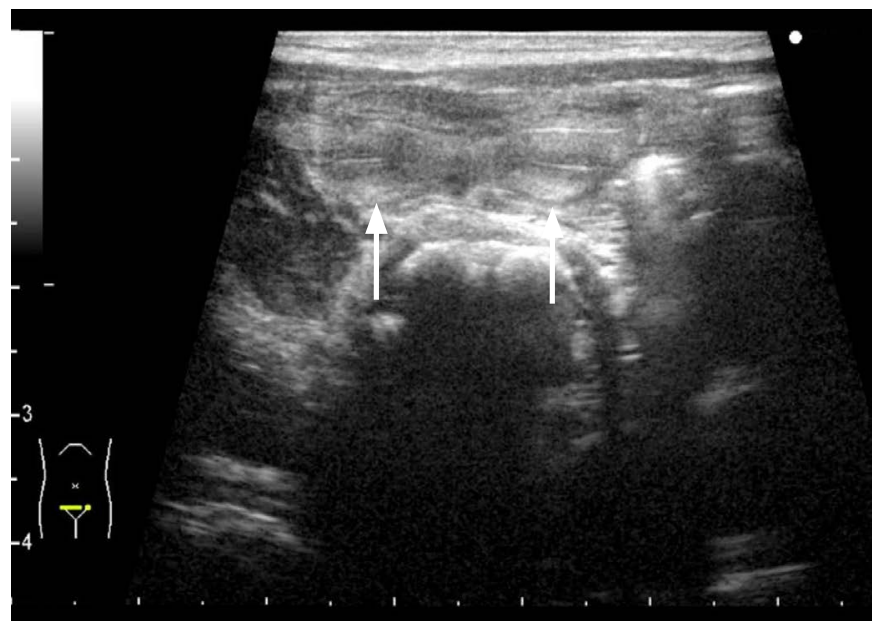

B

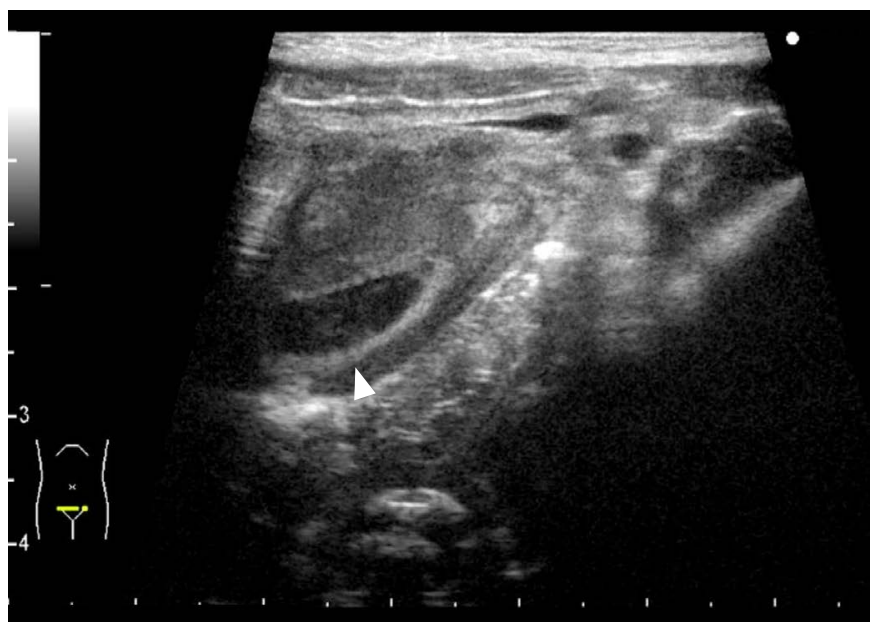

D

Fig. 12. Right renal agenesis with duplicated uterus and ipsilateral vaginal fluid (2-day-old neonate).

A. The right kidney shows agenesis. B-D. A pelvic scan clearly shows the duplicated uterus (arrows in B and C), with intravaginal fluid ipsilateral to renal agenesis (arrowheads $C$ and D), suggesting obstructed hemivagina and ipsilateral renal anomaly. The uterus is mature in this period, in contrast to that of a 6 -year-old girl, shown in Fig. 13. This period is suitable for screening for uterine anomalies. 


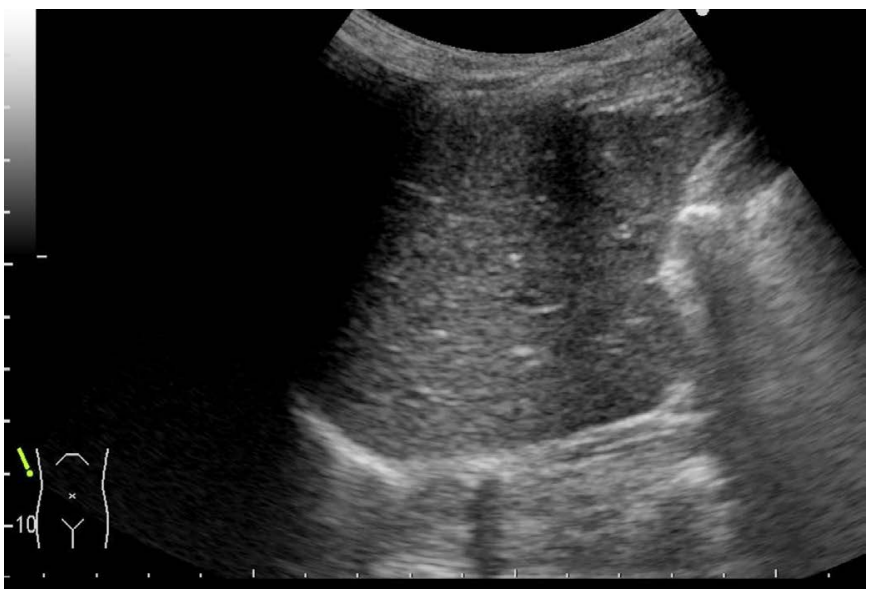

A

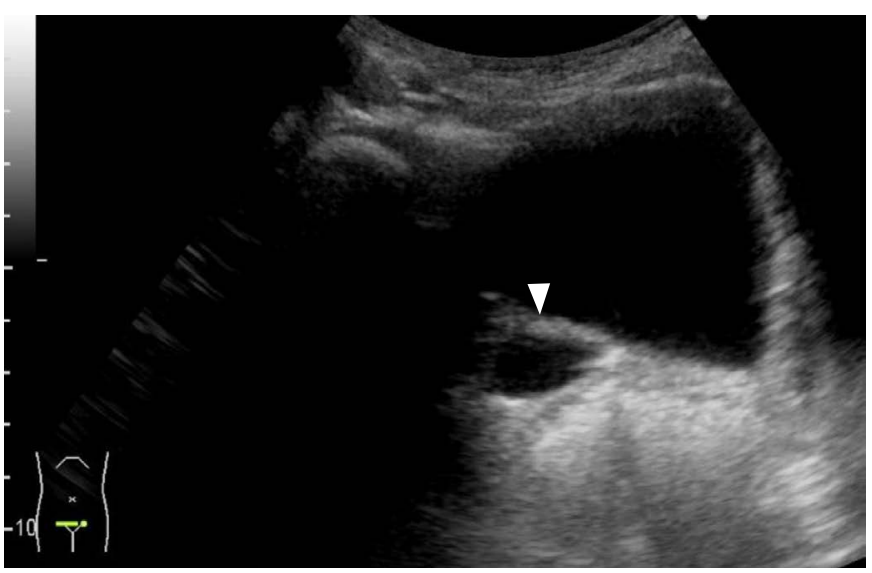

C

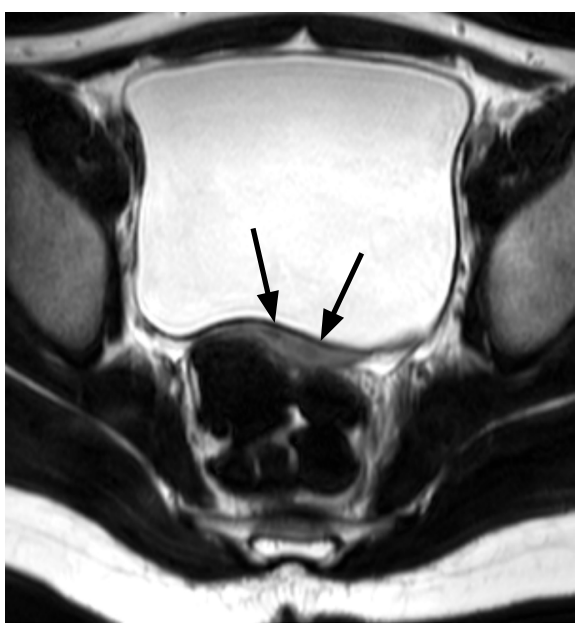

E

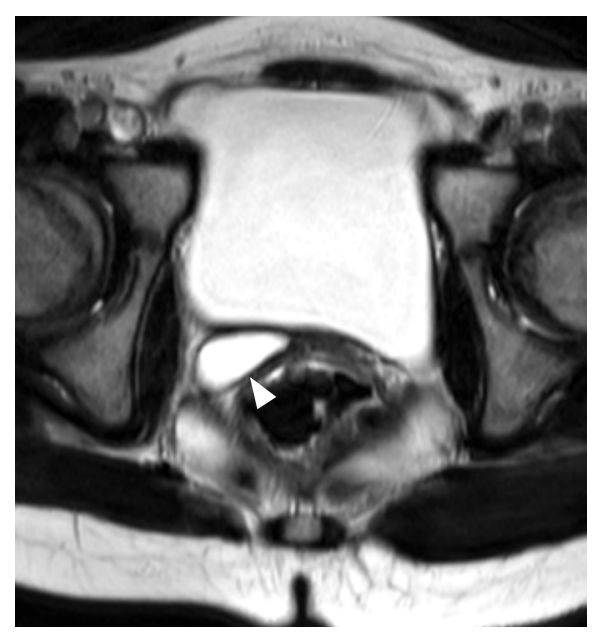

$\mathrm{F}$

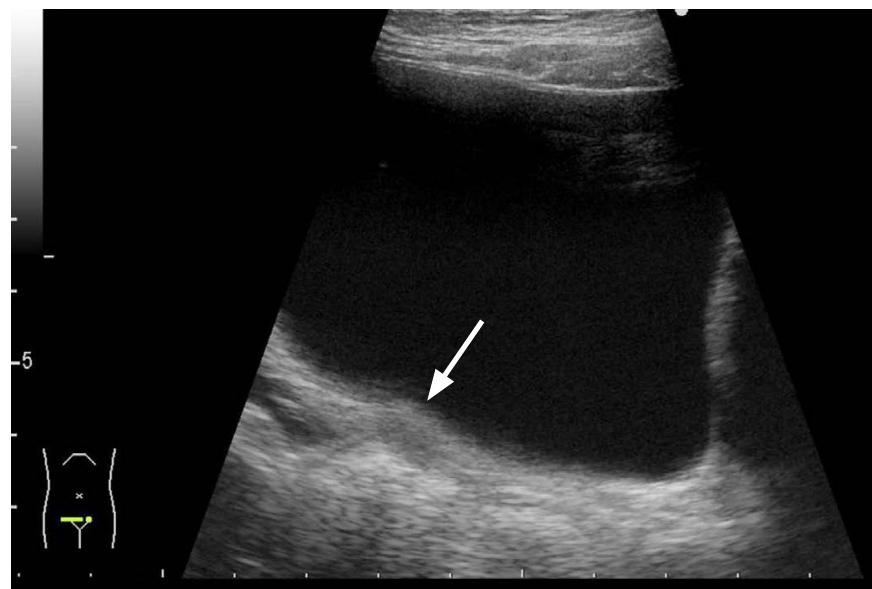

B

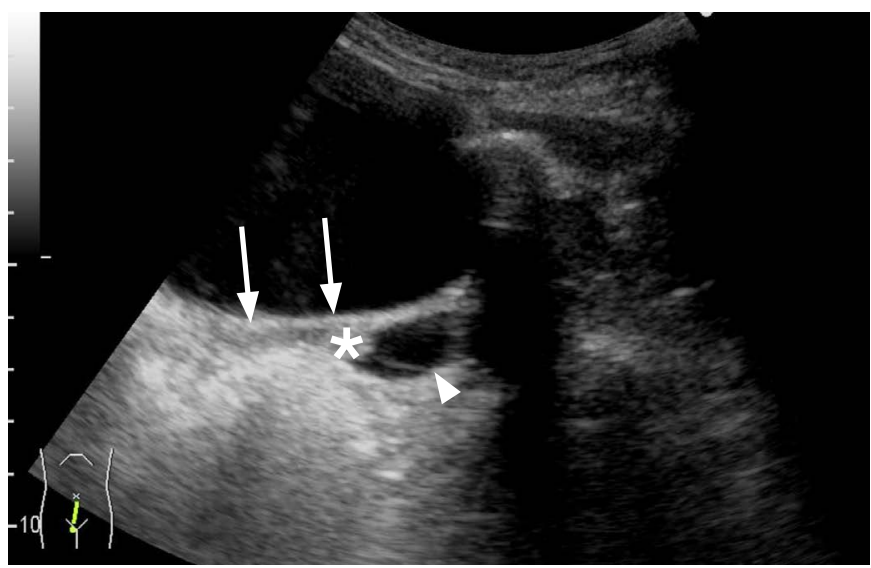

D

Fig. 13. Right renal dysplasia with Müllerian duct anomalies with ipsilateral vaginal fluid (6-year-old girl).

A. The right kidney was not seen due to atrophy from the previously diagnosed multicystic dysplastic kidney. B-D. Intravaginal fluid is seen ipsilateral to renal dysplasia (arrowheads in C [axial image] and $D$ [sagittal image]). The asterisk in $\mathrm{D}$ indicates the vaginal portion of the uterine cervix. The uterine anomaly could not be recognized due to its small size at her age (arrows in B [axial image] and $D$ [sagittal image]). E. On magnetic resonance imaging, two lumina were barely recognized (arrows). F. A caudal slice shows that the vaginal fluid was ipsilateral to renal dysplasia (arrowhead). The size of the uterus is small at this age, in contrast to Fig, 12 in a neonate. Uterine anomalies should be screened during the neonatal period. 
with routine US. In patients with renal dysplasia, the importance of investigating hemiuterine atresia has been stressed [91]. In the neonatal period, the uterus is relatively large because of maternal and placental hormones, and is suitable for the investigation of uterine anomalies (Fig. 12). However, the uterus becomes smaller after this period until adolescence and is difficult to see whether a uterine anomaly exists (Fig. 13). Thus, in cases of renal dysplasia, especially renal aplasia, an investigation to determine whether uterovaginal anomalies are present is recommended in the neonatal period [92].

\section{Conclusion}

The US of pediatric urogenital emergencies is reviewed in this article. Although many pitfalls exist in making a correct diagnosis, knowledge of the correct approach can be of great help. New techniques, including elastography, 3-dimensional US and CEUS, are also discussed here. These techniques should be used as additional tools for making correct diagnoses.

ORCID: Masahiro Kitami: http://orcid.org/0000-0003-3116-5441

\section{Conflict of Interest}

No potential conflict of interest relevant to this article was reported.

\section{Supplementary Material}

Video clip 1. Normal testicular appendage in sagittal view scanned from lateral to medial side.

Video clip 2. Testicular appendage torsion in sagittal view scanned from lateral to medial side.

Video clip 3. Twisted pedicle (whirlpool sign) in ovarian torsion.

\section{References}

1. Rosado E, Riccabona M. Off-label use of ultrasound contrast agents for intravenous applications in children: analysis of the existing literature. J Ultrasound Med 2016;35:487-496.

2. Ben-Chaim J, Leibovitch I, Ramon J, Winberg D, Goldwasser B. Etiology of acute scrotum at surgical exploration in children, adolescents and adults. Eur Urol 1992;21:45-47.

3. Dogra VS, Gottlieb RH, Oka M, Rubens DJ. Sonography of the scrotum. Radiology 2003;227:18-36.

4. Ishizuka E, Noguchi S, Sato K, Iwasaki A, Fukuoka H. A classification for intravaginal torsion of the testis. Eur Urol 1988;15:108-112.

5. Riccabona M, Darge K, Lobo ML, Ording-Muller LS, Augdal TA, Avni
FE, et al. ESPR Uroradiology Taskforce: imaging recommendations in paediatric uroradiology, part VIII: retrograde urethrography, imaging disorder of sexual development and imaging childhood testicular torsion. Pediatr Radiol 2015;45:2023-2028.

6. Pogorelic Z, Mrklic I, Juric I. Do not forget to include testicular torsion in differential diagnosis of lower acute abdominal pain in young males. J Pediatr Urol 2013;9(6 Pt B):1161-1165.

7. Kaye JD, Shapiro EY, Levitt SB, Friedman SC, Gitlin J, Freyle J, et al. Parenchymal echo texture predicts testicular salvage after torsion: potential impact on the need for emergent exploration. J Urol 2008;180(4 Suppl):1733-1736.

8. Burks DD, Markey BJ, Burkhard TK, Balsara ZN, Haluszka MM, Canning DA. Suspected testicular torsion and ischemia: evaluation with color Doppler sonography. Radiology 1990;175:815-821.

9. Gunther P, Schenk JP, Wunsch R, Holland-Cunz S, Kessler U, Troger J, et al. Acute testicular torsion in children: the role of sonography in the diagnostic workup. Eur Radiol 2006;16:2527-2532.

10. Waldert M, Klatte T, Schmidbauer J, Remzi M, Lackner J, Marberger M. Color Doppler sonography reliably identifies testicular torsion in boys. Urology 2010;75:1170-1174.

11. Yagil Y, Naroditsky I, Milhem J, Leiba R, Leiderman M, Badaan S, et al. Role of Doppler ultrasonography in the triage of acute scrotum in the emergency department. J Ultrasound Med 2010;29:11-21.

12. Barth RA, Shortliffe LD. Normal pediatric testis: comparison of power Doppler and color Doppler US in the detection of blood flow. Radiology 1997;204:389-393.

13. Dogra VS, Rubens DJ, Gottlieb RH, Bhatt S. Torsion and beyond: new twists in spectral Doppler evaluation of the scrotum. J Ultrasound Med 2004;23:1077-1085.

14. Yusuf GT, Sidhu PS. A review of ultrasound imaging in scrotal emergencies. J Ultrasound 2013;16:171-178.

15. Sung EK, Setty BN, Castro-Aragon I. Sonography of the pediatric scrotum: emphasis on the Ts: torsion, trauma, and tumors. AJR Am J Roentgenol 2012;198:996-1003.

16. Vijayaraghavan SB. Sonographic differential diagnosis of acute scrotum: real-time whirlpool sign, a key sign of torsion. J Ultrasound Med 2006;25:563-574.

17. Schulsinger D, Glassberg K, Strashun A. Intermittent torsion: association with horizontal lie of the testicle. J Urol 1991;145:10531055.

18. Eaton SH, Cendron MA, Estrada CR, Bauer SB, Borer JG, Cilento $B G$, et al. Intermittent testicular torsion: diagnostic features and management outcomes. J Urol 2005;174(4 Pt 2):1532-1535.

19. Munden MM, Williams JL, Zhang W, Crowe JE, Munden RF, Cisek LJ. Intermittent testicular torsion in the pediatric patient: sonographic indicators of a difficult diagnosis. AJR Am J Roentgenol 2013;201:912-918.

20. Hayn MH, Herz DB, Bellinger MF, Schneck FX. Intermittent torsion of the spermatic cord portends an increased risk of acute testicular 
infarction. J Urol 2008;180(4 Suppl):1729-1732.

21. Baud C, Veyrac C, Couture A, Ferran JL. Spiral twist of the spermatic cord: a reliable sign of testicular torsion. Pediatr Radiol 1998;28:950-954.

22. Arce JD, Cortes M, Vargas JC. Sonographic diagnosis of acute spermatic cord torsion. Rotation of the cord: a key to the diagnosis. Pediatr Radiol 2002;32:485-491.

23. Galina P, Dermentzoglou V, Baltogiannis N, Zarifi M. Sonographic appearances of the epididymis in boys with acute testicular torsion but preserved testicular blood flow on color Doppler. Pediatr Radiol 2015:45:1661-1671.

24. Prando D. Torsion of the spermatic cord: the main gray-scale and doppler sonographic signs. Abdom Imaging 2009;34:648-661.

25. Moschouris H, Stamatiou K, Lampropoulou E, Kalikis D, Matsaidonis D. Imaging of the acute scrotum: is there a place for contrastenhanced ultrasonography? Int Braz J Urol 2009;35:692-702.

26. Sriprasad S, Kooiman GG, Muir GH, Sidhu PS. Acute segmental testicular infarction: differentiation from tumour using high frequency colour Doppler ultrasound. Br J Radiol 2001;74:965-967.

27. Kantarci F, Cebi Olgun D, Mihmanli I. Shear-wave elastography of segmental infarction of the testis. Korean J Radiol 2012;13:820822.

28. Zeng B, Chen F, Qiu S, Luo Y, Zhu Z, Chen R, et al. Application of quasistatic ultrasound elastography for examination of scrotal lesions. J Ultrasound Med 2016;35:253-261.

29. Herek D, Herek $O$, Akbulut M, Ufuk F. Role of strain elastography in the evaluation of testicular torsion: an experimental study. J Ultrasound Med 2016;35:2149-2158.

30. Zhang X, Lv F, Tang J. Shear wave elastography (SWE) is reliable method for testicular spermatogenesis evaluation after torsion. Int J Clin Exp Med 2015;8:7089-7097.

31. Basta AM, Courtier J, Phelps A, Copp HL, MacKenzie JD. Scrotal swelling in the neonate. J Ultrasound Med 2015;34:495-505.

32. Kaye JD, Levitt SB, Friedman SC, Franco I, Gitlin J, Palmer LS. Neonatal torsion: a 14-year experience and proposed algorithm for management. J Urol 2008;179:2377-2383.

33. Mano R, Livne PM, Nevo A, Sivan B, Ben-Meir D. Testicular torsion in the first year of life: characteristics and treatment outcome. Urology 2013;82:1132-1137.

34. Traubici J, Daneman A, Navarro O, Mohanta A, Garcia C. Original report. Testicular torsion in neonates and infants: sonographic features in 30 patients. AJR Am J Roentgenol 2003;180:11431145.

35. Lee YS, Kim MJ, Han SW, Lee HS, Im YJ, Shin HJ, et al. Superb microvascular imaging for the detection of parenchymal perfusion in normal and undescended testes in young children. Eur J Radiol 2016;85:649-656.

36. Akin EA, Khati NJ, Hill MC. Ultrasound of the scrotum. Ultrasound Q 2004;20:181-200.
37. Cappele O, Liard A, Barret E, Bachy B, Mitrofanoff P. Epididymitis in children: is further investigation necessary after the first episode? Eur Urol 2000;38:627-630.

38. Merlini E, Rotundi F, Seymandi PL, Canning DA. Acute epididymitis and urinary tract anomalies in children. Scand I Urol Nephrol 1998:32:273-275.

39. Hudnall TW, Meservy C. Vas deferens ectopia: an uncommon finding. Pediatr Radiol 2004;34:179.

40. Karmazyn B, Kaefer M, Kauffman S, Jennings SG. Ultrasonography and clinical findings in children with epididymitis, with and without associated lower urinary tract abnormalities. Pediatr Radiol 2009;39:1054-1058.

41. Karmazyn B, Steinberg R, Kornreich L, Freud E, Grozovski S, Schwarz $\mathrm{M}$, et al. Clinical and sonographic criteria of acute scrotum in children: a retrospective study of 172 boys. Pediatr Radiol 2005;35:302-310.

42. Jee WH, Choe BY, Byun JY, Shinn KS, Hwang TK. Resistive index of the intrascrotal artery in scrotal inflammatory disease. Acta Radiol 1997;38:1026-1030.

43. Baldisserotto M. Scrotal emergencies. Pediatr Radiol 2009;39:516521.

44. Aigner F, De Zordo T, Pallwein-Prettner L, Junker D, Schafer G, Pichler $R$, et al. Real-time sonoelastography for the evaluation of testicular lesions. Radiology 2012;263:584-589.

45. Boettcher M, Bergholz R, Krebs TF, Wenke K, Treszl A, Aronson DC, et al. Differentiation of epididymitis and appendix testis torsion by clinical and ultrasound signs in children. Urology 2013;82:899-904.

46. Hesser U, Rosenborg M, Gierup J, Karpe B, Nystrom A, Hedenborg L. Gray-scale sonography in torsion of the testicular appendages. Pediatr Radiol 1993;23:529-532.

47. Baldisserotto M, de Souza JC, Pertence AP, Dora MD. Color Doppler sonography of normal and torsed testicular appendages in children. AJR Am J Roentgenol 2005;184:1287-1292.

48. Park SJ, Kim HL, Yi BH. Sonography of intrascrotal appendage torsion: varying echogenicity of the torsed appendage according to the time from onset. J Ultrasound Med 2011;30:1391-1396.

49. Park SJ, Lee HK, Yi BH, Cha JG, Joh JH, Hong HS, et al. Manual reduction of torsion of an intrascrotal appendage under ultrasonographic monitoring. J Ultrasound Med 2007;26:293-299.

50. Lev M, Ramon J, Mor Y, Jacobson JM, Soudack M. Sonographic appearances of torsion of the appendix testis and appendix epididymis in children. J Clin Ultrasound 2015;43:485-489.

51. Guichard G, El Ammari J, Del Coro C, Cellarier D, Loock PY, Chabannes $E$, et al. Accuracy of ultrasonography in diagnosis of testicular rupture after blunt scrotal trauma. Urology 2008;71:5256.

52. Kim SH, Park S, Choi SH, Jeong WK, Choi JH. The efficacy of magnetic resonance imaging for the diagnosis of testicular rupture: a prospective preliminary study. J Trauma 2009;66:239-242. 
53. Klin B, Lotan G, Efrati Y, Zlotkevich L, Strauss S. Acute idiopathic scrotal edema in children: revisited. J Pediatr Surg 2002;37:12001202.

54. Geiger J, Epelman M, Darge K. The fountain sign: a novel color Doppler sonographic finding for the diagnosis of acute idiopathic scrotal edema. J Ultrasound Med 2010;29:1233-1237.

55. Lee A, Park SJ, Lee HK, Hong HS, Lee BH, Kim DH. Acute idiopathic scrotal edema: ultrasonographic findings at an emergency unit. Eur Radiol 2009; 19:2075-2080.

56. Focseneanu MA, Omurtag K, Ratts VS, Merritt DF. The autoamputated adnexa: a review of findings in a pediatric population. J Pediatr Adolesc Gynecol 2013;26:305-313.

57. Anders JF, Powell EC. Urgency of evaluation and outcome of acute ovarian torsion in pediatric patients. Arch Pediatr Adolesc Med 2005; 159:532-535.

58. Servaes S, Zurakowski D, Laufer MR, Feins N, Chow IS. Sonographic findings of ovarian torsion in children. Pediatr Radiol 2007;37:446451.

59. Oltmann SC, Fischer A, Barber R, Huang R, Hicks B, Garcia N. Cannot exclude torsion: a 15-year review. J Pediatr Surg 2009;44:1212-1216.

60. Warner MA, Fleischer AC, Edell SL, Thieme GA, Bundy AL, Kurtz $A B$, et al. Uterine adnexal torsion: sonographic findings. Radiology 1985;154:773-775.

61. Oltmann SC, Fischer A, Barber R, Huang R, Hicks B, Garcia N. Pediatric ovarian malignancy presenting as ovarian torsion: incidence and relevance. J Pediatr Surg 2010;45:135-139.

62. Graif M, Itzchak Y. Sonographic evaluation of ovarian torsion in childhood and adolescence. AJR Am J Roentgenol 1988;150:647649.

63. Graif M, Shalev J, Strauss S, Engelberg S, Mashiach S, Itzchak Y. Torsion of the ovary: sonographic features. AJR Am J Roentgenol 1984;143:1331-1334.

64. Sibal M. Follicular ring sign: a simple sonographic sign for early diagnosis of ovarian torsion. J Ultrasound Med 2012;31:18031809.

65. Kiechl-Kohlendorfer U, Maurer K, Unsinn KM, Gassner I. Fluiddebris level in follicular cysts: a pathognomonic sign of ovarian torsion. Pediatr Radiol 2006;36:421-425.

66. Valsky DV, Esh-Broder E, Cohen SM, Lipschuetz M, Yagel S. Added value of the gray-scale whirlpool sign in the diagnosis of adnexal torsion. Ultrasound Obstet Gynecol 2010;36:630-634.

67. Stark JE, Siegel MJ. Ovarian torsion in prepubertal and pubertal girls: sonographic findings. AJR Am J Roentgenol 1994;163:14791482.

68. Naiditch JA, Barsness KA. The positive and negative predictive value of transabdominal color Doppler ultrasound for diagnosing ovarian torsion in pediatric patients. J Pediatr Surg 2013;48:12831287.
69. Mashiach R, Melamed N, Gilad N, Ben-Shitrit G, Meizner I. Sonographic diagnosis of ovarian torsion: accuracy and predictive factors. J Ultrasound Med 2011;30:1205-1210.

70. Fleischer AC, Brader KR. Sonographic depiction of ovarian vascularity and flow: current improvements and future applications. J Ultrasound Med 2001;20:241-250.

71. Ben-Ami M, Perlitz $Y$, Haddad S. The effectiveness of spectral and color Doppler in predicting ovarian torsion: a prospective study. Eur J Obstet Gynecol Reprod Biol 2002;104:64-66.

72. Yaman C, Ebner T, Jesacher K. Three-dimensional power Doppler in the diagnosis of ovarian torsion. Ultrasound Obstet Gynecol 2002;20:513-515.

73. Zanforlin Filho SM, Araujo Junior E, Serafini P, Guimaraes Filho HA, Pires CR, Nardozza LM, et al. Diagnosis of ovarian torsion by threedimensional power Doppler in first trimester of pregnancy. J Obstet Gynaecol Res 2008;34:266-270.

74. Kupesic S, Plavsic BM. Adnexal torsion: color Doppler and threedimensional ultrasound. Abdom Imaging 2010;35:602-606.

75. Brown JM, Taylor KJ, Alderman JL, Quedens-Case C, Greener Y. Contrast-enhanced ultrasonographic visualization of gonadal torsion. J Ultrasound Med 1997;16:309-316.

76. Svensson JF, Larsson A, Uusijarvi J, von Sivers K, Kaiser S. Oophoropexy, hyperbaric oxygen therapy, and contrast-enhanced ultrasound after asynchronous bilateral ovarian torsion. J Pediatr Surg 2008:43:1380-1384.

77. Vijayaraghavan SB. Sonographic whirlpool sign in ovarian torsion. J Ultrasound Med 2004;23:1643-1649.

78. Lee EJ, Kwon HC, Joo HJ, Suh JH, Fleischer AC. Diagnosis of ovarian torsion with color Doppler sonography: depiction of twisted vascular pedicle. J Ultrasound Med 1998;17:83-89.

79. Kim HS, Yoo SY, Cha MJ, Kim JH, Jeon TY, Kim WK. Diagnosis of neonatal ovarian torsion: Emphasis on prenatal and postnatal sonographic findings. J Clin Ultrasound 2016;44:290-297.

80. Choi KH, Baek HJ. Incarcerated ovarian herniation of the canal of Nuck in a female infant: Ultrasonographic findings and review of literature. Ann Med Surg (Lond) 2016;9:38-40.

81. Hughes P, Abdelhafeez A, Byrne AT, Real D, Gillick J. A paediatric hernia with a Twist: the presentation, imaging findings and management of a strangulated ovarian hernia. Ir Med J 2015;108:282-283.

82. Hyun PM, Jung AY, Lee Y, Yang I, Yang DH, Hwang JY. CT and US findings of ovarian torsion within an incarcerated inguinal hernia. Emerg Radiol 2015;22:91-94.

83. Lee J, Scampoli N. Incarcerated ovarian inguinal hernia in a 10-month-old girl. CMAJ 2015;187:596-598.

84. Merriman TE, Auldist AW. Ovarian torsion in inguinal hernias. Pediatr Surg Int 2000;16:383-385.

85. Orazi C, Lucchetti MC, Schingo PM, Marchetti P, Ferro F. HerlynWerner-Wunderlich syndrome: uterus didelphys, blind hemivagina and ipsilateral renal agenesis. Sonographic and MR findings in 11 
cases. Pediatr Radiol 2007;37:657-665.

86. Shavell VI, Montgomery SE, Johnson SC, Diamond MP, Berman JM. Complete septate uterus, obstructed hemivagina, and ipsilateral renal anomaly: pregnancy course complicated by a rare urogenital anomaly. Arch Gynecol Obstet 2009;280:449-452.

87. Herlyn U, Werner H. Simultaneous occurrence of an open Gartnerduct cyst, a homolateral aplasia of the kidney and a double uterus as a typical syndrome of abnormalities. Geburtshilfe Frauenheilkd 1971:31:340-347.

88. Wunderlich M. Unusual form of genital malformation with aplasia of the right kidney. Zentralbl Gynakol 1976;98:559-562.
89. Gazarek F, Kudela M, Zenisek L, Nevrla F. Herlyn-Werner and Wunderlich syndromes (author's transl). Zentralbl Gynakol 1979;101:1411-1415.

90. Aci NM, Acien P. Claiming "new" in what might be an inadequate search. Chin Med J (Engl) 2015;128:2410-2411.

91. Sheih CP, Li YW, Liao YJ, Chen WL, Lin JY, Chen SM. Early detection of unilateral occlusion of duplicated mullerian ducts: the use of serial pelvic sonography for girls with renal agenesis. J Urol 1994;151:708-710.

92. Muller LS. Ultrasound of the paediatric urogenital tract. Eur J Radiol 2014;83:1538-1548. 